\title{
Biological therapies in nonsmall cell lung cancer
}

\author{
Jon Zugazagoitia 1,2,3,6, Sonia Molina-Pinelo ${ }^{1,2,3,6}$, Fernando Lopez-Rios ${ }^{3,4}$ and \\ Luis Paz-Ares ${ }^{1,2,3,5}$
}

Affiliations: ${ }^{1}$ Medical Oncology Dept, Hospital Universitario 12 de Octubre and Instituto de Investigación i+12, Madrid, Spain. ${ }^{2}$ Lung Cancer Group, Clinical Research Program, CNIO (Centro Nacional de Investigaciones Oncológicas), Madrid, Spain. ${ }^{3}$ Centro de Investigación Biomédica en Red de Cáncer (CIBERONC), Spain. ${ }^{4}$ Laboratorio de Dianas Terapéuticas, Hospital Universitario HM Sanchinarro, Madrid, Spain. ${ }^{5}$ Complutense University, Madrid, Spain. ${ }^{6}$ These authors contributed equally to this work.

Correspondence: Luis Paz-Ares, Servicio de Oncología Médica, Hospital Universitario Doce de Octubre, Av. De Córdoba km 5,4, 28041 Madrid, Spain. E-mail: Ipazaresraseom.org

@ERSpublications

Genotype-directed therapies and immune checkpoint inhibitors have improved survival of subset of advanced NSCLC http://ow.ly/4EuI308cj15

Cite this article as: Zugazagoitia J, Molina-Pinelo S, Lopez-Rios F, et al. Biological therapies in nonsmall cell lung cancer. Eur Respir J 2017; 49: 1601520 [https://doi.org/10.1183/13993003.01520-2016].

ABSTRACT Biological therapies have improved survival outcomes of advanced-stage nonsmall cell lung cancer (NSCLC). Genotype-directed therapies have changed treatment paradigms of patients with EGFRmutant and $A L K / R O S 1$-rearranged lung adenocarcinomas, and the list of druggable targets with demonstrated clinical actionability (BRAF, MET, RET, NTRK1 and HER2) continues to expand. Furthermore, we have incrementally understood the mechanisms of cancer immune evasion and foresee ways to effectively circumvent them, particularly at the immune checkpoint level. Drugs targeting the tumour immune-evasive PD-1 pathway have demonstrated remarkable treatment benefits in this disease, with a non-negligible fraction of patients potentially receiving long-term survival benefits. Herein, we briefly discuss the role of various medical disciplines in the management of advanced-stage NSCLC and review the most relevant biological therapies for this disease, with particular emphasis in genotype-directed therapies and immune checkpoint inhibitors.

Received: July 292016 | Accepted after revision: Dec 282016

Conflict of interest: Disclosures can be found alongside this article at erj.ersjournals.com

Copyright @ERS 2017 


\section{Introduction}

Lung cancer is the leading cause of cancer-related mortality worldwide, with an approximate 5-year survival rate of $18 \%$ [1]. According to pathological characteristics, $\sim 80 \%$ of the cases are classified as nonsmall cell lung cancers (NSCLCs). These are further divided in three predominant histological subtypes: adenocarcinoma (50\%), squamous cell carcinoma (40\%) and large cell carcinoma. Small cell lung carcinoma accounts for the remaining 15-20\% of all lung cancers [2]. The vast majority of lung cancer patients are diagnosed with advanced-stage disease.

In parallel to new technology acquisition (e.g. molecular profiling and chemistry plasticity), the growing knowledge of cancer biology has enabled the development of novel biological therapies that target several components of the tumour. These treatments have already impacted the natural history of some specific molecular subsets of lung cancers and this trend is expected to expand in the coming years. In particular, oncogene-targeted therapies for biomarker-selected patients and immune checkpoint inhibitors have changed treatment paradigms and transformed the expected outcomes of a substantial fraction of advanced-stage NSCLC patients. Here, we briefly describe some clinically relevant discoveries related to molecular taxonomy and the role of the immune system in lung cancer, and review the most promising and currently available biological therapies in the field. In this context, we also illustrate the importance of a multidisciplinary management of advanced-stage NSCLC patients.

\section{Multidisciplinary management of advanced-stage NSCLC}

Tumour pathological and molecular subtyping is paramount for advanced-stage NSCLC therapy guidance. In fact, much of the success of systemic treatments for this disease profoundly relies on obtaining sufficient amounts of tumour, and on appropriate sample flow and tissue priorisitation [3], which cannot be optimally accomplished without a multidisciplinary management of these patients. Pulmonologists and radiologists are crucial to rapid diagnosis and performing the safest effective and efficient biopsy procedures. Notably, as we will comment upon later, tumour rebiopsies are evoked as a new standard of care in the management of patients with epidermal growth factor receptor (EGFR)-mutant and anaplastic lymphoma kinase $(A L K)$-rearranged, tyrosine kinase inhibitor (TKI)-resistant tumours, which implies that both disciplines will be involved not only in the initial patient diagnosis but also in later stages of progressive disease and subsequent lines of therapy. In selected patients whose tumours are not accessible for endoscopic or computed tomography-guided core biopsies, the possibility to perform surgical resections from metastatic sites should be discussed in a multidisciplinary team with thoracic or general surgeons. After specimen collection, a lung cancer pathologist must be trained in proper diagnostic, pathological subtyping and molecular subtyping protocols to optimise the use of tissue. This is particularly relevant for small tumour biopsies, in which adequate tissue-sparing protocols must be implemented in each institution. In general, expert panels recommend limiting the use of markers for histological subtyping (e.g. restrict immune staining to thyroid transcription factor 1 and $\mathrm{p} 40$ ) in order to avoid tissue waste for further genomic characterisation or immune-profiling (e.g. programmed death ligand 1 (PD-L1) expression) of the tumours $[4,5]$, which will ultimately dictate the selection of most of the biological therapies. Importantly, in order for the patients to receive the most appropriate systemic treatment, thoracic oncologists must integrate this pathologic and molecular information into the appropriate clinical context. Finally, during the course of therapy, the help and close collaboration of other various medical specialists (dermatologists, endocrinologists, gastroenterologists, nephrologists, immunologists, etc.) will be needed for early recognition and treatment of toxic effects and therapy-related complications.

\section{Biological therapies for NSCLC}

Oncogene-tailored therapies for molecularly selected patients

NSCLC is a paradigmatic example illustrating the success of genotype-driven precision oncology. Many molecular aberrations defining particular subsets of lung cancers can be specifically targeted with oncogene-tailored therapies. High-resolution and high-throughtput molecular profiling of NSCLCs has revealed that the majority of the molecular alterations, and particularly those that are therapeutically vulnerable, are mostly histology specific [3]. Successful identification of biomarkers with therapeutic purposes has been mainly made in lung adenocarcinoma. Different types of genomic alterations involving multiple driver kinase genes, such as EGFR, KRAS, ALK, ROS1, BRAF, MET, RET, neurotrophic receptor tyrosin kinase (NTRK) and human EGFR2 (HER2), represent specific molecular subtypes of pulmonary adenocarcinomas, with distinct biology, epidemiology, prognosis and therapeutic susceptibilities [3, 6] (tables 1-3). In contrast, the genomic portrait of squamous cell lung carcinoma is mostly composed of inactivating mutations in tumour suppressor genes or mutations in oncogenes not amenable to direct therapeutic targeting $[58,59]$. The few potentially actionable alterations commonly found in squamous cell lung cancers, such as fibroblast growth factor receptor 1 (FGFR1) amplification, or phosphoinositol 


\begin{tabular}{|c|c|c|c|c|c|c|c|c|c|}
\hline Genomic features & $\begin{array}{l}\text { First- and } \\
\text { second-generation } \\
\text { EGFR TKIs }\end{array}$ & RR & $\begin{array}{l}\text { mPFS } \\
\text { months }\end{array}$ & $\begin{array}{c}\text { Selected } \\
\text { third-generation } \\
\text { EGFR TKIs } \\
\text { overcoming } \\
\text { target-mediated } \\
\text { resistance }\end{array}$ & $\begin{array}{l}\text { Clinical trial } \\
\text { phase (study } \\
\text { acronym) }\end{array}$ & $\begin{array}{c}\text { Total/ } \\
\text { T790M }^{+} \\
\text {n/n }\end{array}$ & Context & $\begin{array}{l}\text { RR in } \\
\text { T790M }^{+}\end{array}$ & $\begin{array}{l}\text { mPFS in } \\
\text { T790M }^{+} \\
\text {months }\end{array}$ \\
\hline $\begin{array}{l}\text { Common }(90 \%) \\
\text { del19, exon } 21 \\
\text { L858R }\end{array}$ & & & & & I [9] (AURA1) & $60 /-$ & $\begin{array}{c}\text { TKI } \\
\text { naive }\end{array}$ & $77 \%$ & $>19$ \\
\hline \multirow{4}{*}{$\begin{array}{l}\text { Uncommon (10\%) } \\
\text { e.g. exon } 18 \\
\text { G719X, exon } 21 \\
\text { L861Q }\end{array}$} & & & & Rociletinib" & $\begin{array}{l}\text { I/II [10] } \\
\text { (TIGERX) }\end{array}$ & $130 / 51$ & $\begin{array}{c}\text { TKI } \\
\text { resistant }\end{array}$ & $\sim 30 \%$ & 6.1 \\
\hline & & & & EGF816 & I [12] & $152 / 152$ & $\begin{array}{c}\text { TKI } \\
\text { resistant }\end{array}$ & $46.9 \%$ & $9.7 \mathrm{~m}$ \\
\hline & & & & ASP8273 & $\begin{array}{c}\text { I/II [13] } \\
\text { (NA cohort) }\end{array}$ & $60 / 40$ & $\begin{array}{c}\text { TKI } \\
\text { resistant }\end{array}$ & $65 \%$ & $6.7 \mathrm{~m}$ \\
\hline & & & & & $\begin{array}{c}\text { I [14] (Japan } \\
\text { cohort) }\end{array}$ & $45 / 15$ & $\begin{array}{c}\text { TKI } \\
\text { resistant }\end{array}$ & $80 \%$ & \\
\hline
\end{tabular}

TKI: tyrosine-kinase inhibitor; RR: response rate; mPFS: median progression-free survival; NA: North American. ${ }^{\text {: }}$ European Medicines Agency and US Food and Drug Administration approved; ${ }^{\text {? }}$ no longer in clinical development.

3-kinase $(P I 3 K)$ and discoidin domain-containing receptor $2(D D R 2)$ mutations are challenging targets, and no specific inhibitors have proven clinical efficacy as yet [59].

\section{Approved targets \\ Sensitising EGFR activating mutations}

Approximately $10-15 \%$ of Caucasian lung adenocarcinoma patients harbour EGFR activating mutations (exons 18-21). The most common alterations include exon 19 deletions and a point mutation at position 858 in exon 21 (L858R), accounting for up to 85-90\% of EGFR mutations in the clinic. Both are sensitive to EGFR TKIs and are known as EGFR "sensitising mutations". The remaining $10-15 \%$ of the cases are EGFR "uncommon mutations" and show variable TKI sensitivity [7]. Mutant receptors have constitutive, ligand-independent tyrosine kinase activity. This activation stimulates several intracellular signalling cascades, such as the PI3K/Akt, RAS/RAF/ERK, phospholipase $\mathrm{C} \gamma$, Src kinase and STAT signalling pathways, and has profound consequences in tumour growth, survival and progression potential [60].

Following the results of the landmark IPASS trial, six molecularly selected randomised controlled trials consistently demonstrated significantly higher overall response rates (56-82\% versus $15-47 \%$ ) and longer progression-free survival (PFS) (9.2-13.1 versus 4.6-6.9 months) in favour of first-generation (gefitinib and erlotinib) or second-generation (afatinib) EGFR TKIs compared to standard platinum-based chemotherapy (table 1). None of the studies demonstrated overall survival (OS) benefits, at least partially due to the high treatment crossover at disease progression [7]. These three drugs are currently approved without distinctions for EGFR-mutant NSCLCs. Various meta-analyses have suggested a comparable clinical activity among them (particularly between first-generation TKIs), with some differences in adverse event profile $[7,61,62]$. However, the question of whether the choice between first-and second-generation inhibitors impacts treatment outcomes has not been fully answered to date. Two randomised trials comparing gefitinib with afatinib (Lux-Lung 7) and gefitinib with dacomitinib (ARCHER 1050 (www.clinicaltrials.gov identifier NCT01774721) were designed to address this issue. Data from the LUX-Lung 7 trial have recently been reported. Afatinib significantly increased response rates (70\% versus 56\%, $\mathrm{p}=0.0083$ ), median PFS (11 versus 10.9 months; hazard ratio (HR) 0.73, 95\% CI 0.57-0.95; $\mathrm{p}=0.0195$ ) and median time to treatment failure (13.7 versus 11.5 months; HR $0.73,95 \%$ CI $0.58-0.92 ; \mathrm{p}=0.0073$ ) over gefinitib. However, there were no OS differences among treatment arms in this phase IIb trial $(\mathrm{n}=319)$. Overall, treatment-related adverse events (mainly skin rash and diarrhoea) and serious adverse 
events (10.6\% (6.3\% diarrhoea) versus $4.4 \%$ (2.5\% interstitial lung disease)) were more common with afatinib [63]. Therefore, this trial suggests that the emergence of acquired resistance might be delayed with second-generation, compared to first-generation, TKIs, but whether these modest differences are clinically relevant for patients is arguable for many physicians.

Despite initial clinical benefit, all patients ultimately progress on first/second-generation EGFR TKI treatment. The acquisition of a secondary mutation in exon 20 (T790M) is the most common EGFR-dependent acquired resistant mechanism, observed in up to 50-60\% of these patients [64]. Third-generation EGFR TKIs are EGFR mutant-selective inhibitors with a particularly potent activity against the T790M mutant kinase, preserving activity against the activating mutation but sparing the wild-type receptor. In turn, they show significantly less toxicity attributable to wild-type EGFR inhibition in normal tissues (skin rash and diarrhoea). Osimertinib has succeeded in overcoming a major proportion of EGFR T790M-driven acquired resistance. Pooled data from phase I and phase II trials validated an overall response rate of $66 \%$ in a total of 411 resistant, T790M-mutant NSCLCs (table 1) [8]. In marked contrast, its activity dropped to $20-35 \%$ of overall response rates and $<3$ months of PFS in patients with T790M-negative tumours [65]. These results largely exceed the expected benefits for standard chemotherapy and have allowed the recent approval of osimertinib by the main regulatory authorities (the US Food and Drug Administration (FDA) and European Medicines Agency (EMA)) for patients with $\mathrm{T} 90 \mathrm{M}^{+}$tumours progressing on first/second-generation EGFR TKIs. Results from confirmatory phase III trials are pending (NCT02151981). Although similar efficacy outcomes were initially reported for rociletinib [66], the updated response rate data $(\sim 30 \%)$ [10] suggest a lower activity of this drug compared to osimertinib and it is not currently in clinical development. There are other novel third-generation TKIs in early phases of development, including HM61713, ASP8273, EGF816, AZD3759 and HMPL-813 (table 1).

Nevertheless, as with first- or second-generation inhibitors, acquired resistance to third-generation EGFR TKIs will inevitably develop. Loss of T790M has been described in a significant proportion of cases treated both with osimertinib and rociletinib $[67,68]$. In addition, a tertiary C797S mutation is detectable in about $30 \%$ of patients treated with osimertinib [67]. Novel allosteric inhibitors selectively targeting EGFR C797S mutants have been already discovered but have not yet been clinically tested [69].

On the other hand, non-EGFR-dependent mechanisms of acquired resistance have been also identified in patients treated with first/second-generation (40\%) and third-generation (less known, probably 50-60\%) TKIs [7]. These mechanisms rely on activation of alternative pathways ("by-pass tracks") reinstating cell survival and proliferation. Targeting those oncogenic events are rational combinations to overcome resistance. For instance, MET oncogene dysregulation is found in $\sim 10 \%$ of the acquired resistant cases. In a molecularly selected phase Ib/II trial, combined treatment of gefitinib plus the c-MET-selective TKI inhibitor capmatinib showed partial responses in $50 \%$ of the patients harbouring highly $M E T$-amplified tumours, with manageable toxicities [70].

With the aim to demonstrate whether front-line third-generation EGFR TKIs delay the development of EGFR-dependent acquired resistance, these drugs are being actively tested in treatment-naïve patients (NCT02296125). Osimertinib treatment has shown a response rate of $77 \%$ and an encouraging median PFS of nearly 20 months in 60 previously untreated EGFR mutant NSCLCs included in the AURA-1 study (table 1) [9]. In order to delay aggressive forms of heterogeneous resistance, upfront combinatorial strategies targeting alternative pathways are also being tested in clinical trials (e.g. third-generation TKIs plus MEK inhibitors; NCT02143466).

Finally, antiangiogenics have demonstrated synergistic clinical activity as first-line combination therapies with EGFR TKIs. Erlotinib plus bevacizumab showed a 6-month PFS improvement over erlotinib alone in a phase II Japanese trial in treatment-naïve patients (16 versus 9.6 months; HR 0.54, 95\% CI 0.36-0.79; $\mathrm{p}=0.0015)$. No unexpected toxicities were reported [71]. The recently presented European, single-arm, phase II BELIEF study confirmed the clinical activity of the front-line front-line combination, particularly for those patients harbouring pre-treatment double-mutant (sensitising mutation plus T790M mutation) tumours (16 months median PFS, 1-year PFS rate 72\%) [72]. Following these results, bevacizumab has gained EMA approval as front-line combination treatment with erlotinib for patients with common sensitising EGFR-mutant tumours, and represents an alternative to first- or second-generation TKI monotherapy in this setting.

ALK rearrangements

Chromosomal $A L K$ rearrangements are found in approximately $3-7 \%$ of NSCLCs. To date, $>27$ fusion variants have been described in human cancer, EML4 being the most frequent $5^{\prime}$ fusion partner. As is the case with other gene fusions in lung cancer (e.g. ROS1, RET and NTRK1), the resulting gene fusion proteins typically induce ligand-independent dimerisation and transphosphorylation of the tyrosine kinase 
domain, resulting in constitutive activation of downstream signalling pathways including PI3K/AKT, RAS/ RAF/ERK and STAT [15].

Crizotinib, a first-generation ALK inhibitor, is an orally bioavailable small molecule that targets ALK, ROS1 and MET tyrosine kinases, and represents the cornestorne of treatment of $A L K$ rearranged lung cancer. Initial phase I (PROFILE 1001) and phase II trials (PROFILE 1005) in molecularly selected and mostly pretreated cohorts demonstrated a significant $60 \%$ response rate and 10-11-months PFS [16]. Subsequently, the randomised phase II PROFILE 1007 study showed better response rate (65\% versus 20\%, $\mathrm{p}<0.001$ ) and PFS (7.7 versus 3.3 months; HR 0.49, 95\% CI $0.37-0.64 ; \mathrm{p}<0.001$ ) than second-line chemotherapy [17]. Finally, crizotinib conferred significant improvements in response rates (74\% versus $45 \%, \mathrm{p}<0.001)$ and PFS (10.9 versus 7 months; HR 0.45, 95\% CI 0.35-0.60; $\mathrm{p}<0.001)$ compared to standard front-line platinum-pemetrexed-based chemotherapy in the PROFILE 1014 trial (table 2) [18].

Similarly to EGFR-mutant cancers, ALK TKI resistance involves ALK-dominant ( 40\%) and ALK-nondominant ( $60 \%)$ mechanisms. Among the former, $30 \%$ of $A L K$-positive NSCLCs treated with crizotinib develop mutations within the ALK tyrosine kinase domain. The ALK L1196M mutation is analogous to the T790M mutation in EGFR-resistant disease [64]. Next-generation ALK inhibitors are not ALK-selective inhibitors, and they variably target other kinases including ROS1, Trk, MET or insulin-like growth factor 1 receptor, among others. Ceritinib and alectinib accumulate the vast majority of the clinical data, but there are other many in different phases of development, including brigatinib, ensartinib, lorlatinib, entrectinib, TSR-011 and X-376. In general, these compounds have been optimised to overcome some of the limitations associated with crizotinib: they show higher potency against wild-type $A L K$, increased but variable

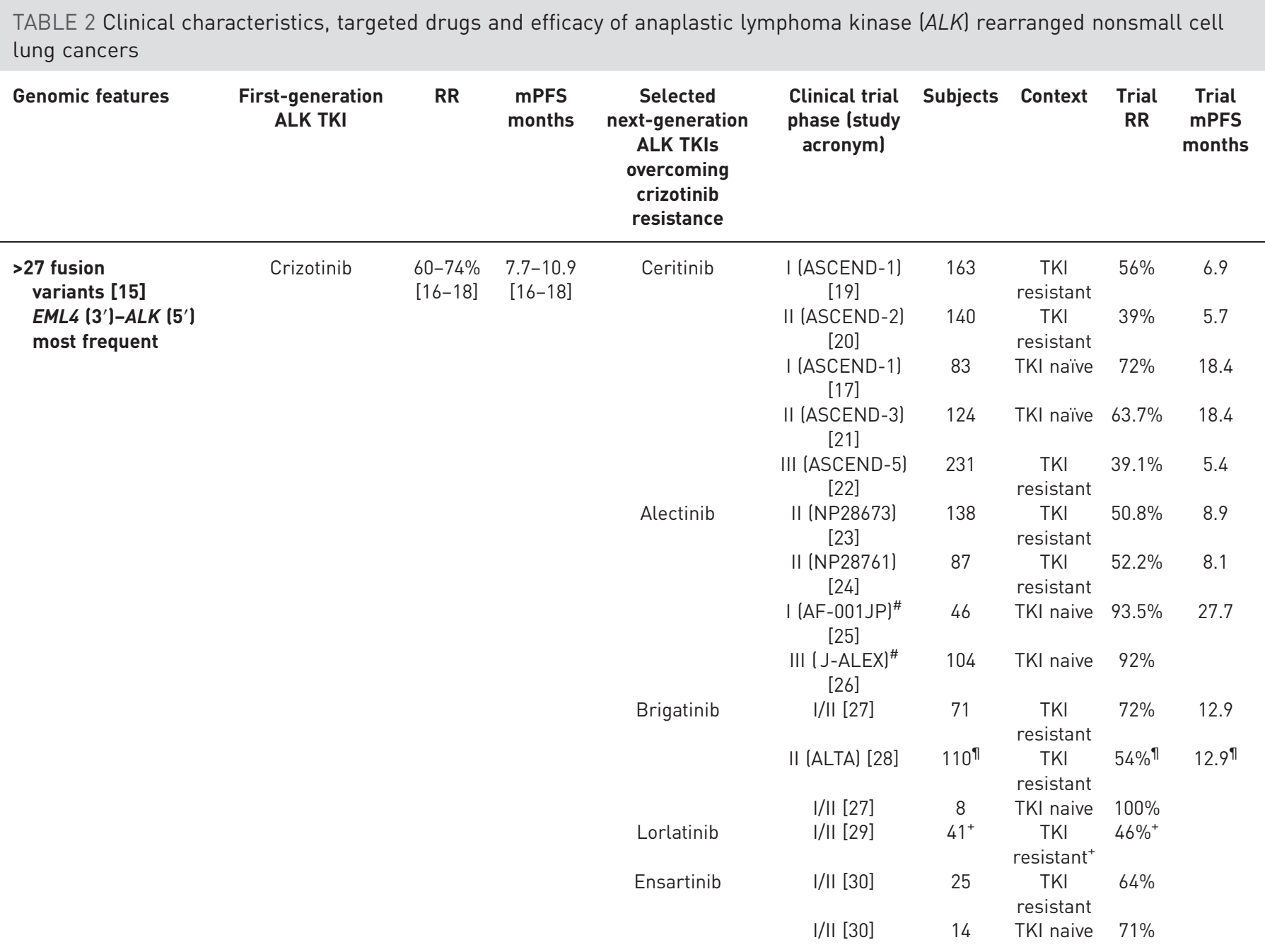

TKI: tyrosine kinase inhibitor; RR: response rate; mPFS: median progression-free survival. ": Japanese study; ": data correspond to brigatinib at $180 \mathrm{mg}$ daily dose; ${ }^{+}$: including patients resistant to more than one ALK TKI. 


\begin{tabular}{|c|c|c|c|c|c|c|c|}
\hline Gene & Genomic alteration & $\begin{array}{l}\text { Prevalence in } \\
\text { Caucasians }\end{array}$ & Clinical features & $\begin{array}{l}\text { Selected drugs with } \\
\text { clinical data available }\end{array}$ & RR & $\begin{array}{l}\text { Selected next-generation } \\
\text { drugs overcoming } \\
\text { acquired resistance }\end{array}$ & $\begin{array}{c}\mathrm{RR} \text { of } \\
\text { next-generation } \\
\text { drug }\end{array}$ \\
\hline ROS1 & $\begin{array}{l}\text { Rearrangements [31] } \\
>9 \text { fusion variants } \\
\text { CD74 }\left(3^{\prime}\right)-R O S 1\left(5^{\prime}\right) \\
\text { most frequent }\end{array}$ & $1-2 \%[31]$ & $\begin{array}{c}\text { AD (rarely SCC) [31] } \\
\text { Never or light smokers } \\
\text { Younger age } \\
\text { Females>males }\end{array}$ & Crizotinib & $72-80 \%[32,33]$ & $\begin{array}{l}\text { Lorlatinib, cabozantinib, } \\
\text { ceritinib, entrectinib, } \\
\text { brigatinib, foretinib }\end{array}$ & $33 \%{ }^{\#}[29]$ \\
\hline BRAF & $\begin{array}{l}\text { Sensitising kinase domain } \\
\text { activating mutations [34] } \\
\text { V600E (50\% of all } \\
\text { cases) }\end{array}$ & $2-4 \%[34]$ & $\begin{array}{l}\text { Mainly AD [34] } \\
\text { Smokers }>\text { nonsmokers } \\
\text { Irrespective of age/sex }\end{array}$ & $\begin{array}{l}\text { Vemurafenib, } \\
\text { dabrafenib, trametinib }\end{array}$ & $32-63 \%[35,36]$ & & \\
\hline \multirow[t]{2}{*}{ MET } & $\begin{array}{l}\text { Amplification } \\
\quad(\text { ratio } \geqslant 5)[37]\end{array}$ & $\sim 3-4 \%[37]$ & $\begin{array}{c}\text { Mostly AD [37] } \\
\text { Smokers nonsmokers } \\
\text { Older age } \\
\text { Females males }\end{array}$ & $\begin{array}{c}\text { Crizotinib, } \\
\text { cabozantinib, capmatinib }\end{array}$ & $67 \%[38]$ & & \\
\hline & Exon 14 mutations $[39,40]$ & $2-3 \%[37,39,40]$ & $\begin{array}{c}\text { AD SCC [41] } \\
\text { Smokers nonsmokers } \\
\text { Older age } \\
\text { Females males }\end{array}$ & $\begin{array}{c}\text { Crizotinib, } \\
\text { cabozantinib, capmatinib }\end{array}$ & $44 \%[42]$ & & \\
\hline RET & $\begin{array}{c}\text { Rearrangements }[43,44] \\
>4 \text { fusion variants } \\
\text { KIF5B }\left(3^{\prime}\right)-R E T\left(5^{\prime}\right) \\
\text { most frequent }\end{array}$ & $\sim 1 \%[44]$ & $\begin{array}{c}\text { AD (rarely } \mathrm{SCC} \text { ) }[43,44] \\
\text { Never or light smokers } \\
\text { Younger age } \\
\text { Females>males }\end{array}$ & $\begin{array}{c}\text { Cabozantinib, vandetanib, } \\
\text { lenvatinib, sorafenib, } \\
\text { sunitinib, alectinib, } \\
\text { ponatinib }\end{array}$ & $16-53 \%[45-48]$ & & \\
\hline NTRK & $\begin{array}{l}\text { Rearrangements [49] } \\
2 \text { fusion variants } \\
\text { MPRIP (3')-NTRK1 (5') } \\
\text { CD74 (3')-NTRK1 (5') }\end{array}$ & $1 \%[50,51]$ & $\begin{array}{c}\text { Mainly AD }[50,51] \\
\text { Smokers>nonsmokers } \\
\text { Irrespective of } \\
\text { age/sex }\end{array}$ & $\begin{array}{l}\text { Entrectinib, } \\
\text { LOX0-01 }\end{array}$ & $\begin{array}{l}\text { Strong responses in } \\
\text { small cohorts and } \\
\text { isolated case reports }\end{array}$ & & \\
\hline HER2 & $\begin{array}{l}\text { Kinase domain activating } \\
\text { mutations: }[52,53] \\
\text { Exon } 20 \text { insertions }\end{array}$ & $1-3 \%[52,53]$ & $\begin{array}{l}\text { AD }[52,53] \\
\text { Never or light smokers } \\
\text { Younger age } \\
\text { Females>males }\end{array}$ & $\begin{array}{c}\text { Afatinib, dacomitinib, } \\
\text { neratinib, trastuzumab, } \\
\text { TDM1 }\end{array}$ & $\begin{array}{c}10-20 \% \\
{[54,55,56,57]}\end{array}$ & & \\
\hline
\end{tabular}

RR: response rate; AD: adenocarcinomal; SCC: squamous cell carcinoma. ${ }^{*}$ : lorlatinib data from a small cohort (n=6) of crizotinib-resistant, $R O S 1^{+}$lung cancers. 
specificity for the different $A L K$ mutant variants and higher central nervous system penetration [73]. Consequently, solid phase II clinical evidence has already shown that second-generation ALK TKIs (ceritinib, alectinib and brigatinib) induce a response in $39-62 \%$ of patients with proven crizotinib resistance, achieving a median PFS of 5.7-12.9 months (table 2) [19, 20, 23, 24, 28]. Confirmatory phase III data in previously treated patients have been already reported for ceritinib, which shows superior response rates $(39.1 \%$ versus 6.9\%) and PFS (5.4 versus 1.6 months; HR 0.49, p<0.001) compared to docetaxel- or pemetrexed-based chemotherapy [22]. In addition, these drugs consistently demonstrate robust and durable central nervous system responses even in patients without prior brain radiotherapy, mirroring the systemic activity $[19,28,74$, 75]. Toxicities differ between drugs and might be relevant in some cases. For instance, overall drug-related adverse events were more frequent in the ceritinib arm (mainly substantial gastrointestinal side-effects and alanine transaminase/aspartate transaminase increase) than in the chemotherapy arm (mainly haematological toxicities) in the ASCEND-5 trial [22]. In contrast, gastrointestinal toxicities are less common with alectinib, and low- to mild-grade myalgia, increased creatine phosphokinase and elevated liver function tests are most commonly observed with this drug [23]. Gastrointestinal events are also relatively common with brigatinib and it is worth noting that early pulmonary events (including dyspnoea, hypoxia and lung opacities) were reported in $6 \%$ of the patients treated with this compound [28]. Approval has been recently granted for ceritinib (FDA and EMA) and alectinib (FDA) for patients progressing on crizotinib.

A recent study has unravelled major clinical mechanisms of acquired resistance to second-generation ALK inhibitors. $A L K$ kinase domain mutations are more frequently detected upon second-generation TKI progression $(\sim 50 \%)$ than upon crizotinib resistance $(\sim 30 \%)$, which is consistent with their higher potency against ALK. Remarkably, each inhibitor is associated with its own spectrum and sensitivity to ALK mutations, and all ALK mutations acquired upon first- and second-generation ALK TKIs seem to predict sensitivity to the third-generation inhibitor lorlatinib [76]. Clinically, lorlatinib has recently shown encouraging activity in a phase I/II study of 41 patients with $A L K^{+}$NSCLCs, mostly refractory to at least one prior TKI, with an objective response rate and median PFS of $46 \%$ and 11.4 months, respectively. Remarkably, a response rate of $42 \%$ and median PFS of 9.2 months were reported for patients refractory to two or more lines of previous ALK TKIs (table 2). Moreover, durable responses were described in patients harbouring G1202R-mutant tumours, an ALK kinase domain mutation conferring clinical resistance to crizotinib, alectinib and ceritinib. Robust central nervous system responses (including leptomeningeal disease) were equally observed. Hypercholesterolaemia and peripheral edoema were the most frequent treatment-related adverse events reported at the recommended phase II dose [29]. Therefore, as next-generation ALK TKIs show distinct sensitivity to ALK mutations and also target different kinases potentially involved in bypass track mediated acquired resistance (e.g. MET), sequential therapy with next-generation ALK TKIs in progressive disease is a viable and clinically feasible treatment option $[29,77]$.

Novel ALK TKIs are also being actively tested in ALK TKI-naïve patients. Single-cohort data with ceritinib, alectinib, brigatinib or ensartinib indicate that crizotinib-naïve patients achieve higher response rates (71-93.5\%) [19, 21, 25, 27, 30] and longer median PFS (18.4-27.7 months) [19, 78] than crizotinib resistant patients (table 2). Recently, important findings from the phase III J-ALEX trial have been reported. In this study, ALK TKI-naïve Japanese NSCLC patients with $A L K^{+}$tumours were randomised to receive front-line alectinib versus crizotinib. Median PFS was significantly longer with alectinib (not reached) than crizotinib (10.2 months) (HR 0.34, 95\% CI 0.17-0.71; p<0.0001) (table 2). Of note, the small subgroup of patients with baseline brain metastases also strongly benefited with front-line alectinib in terms of PFS (HR 0.08). The overall toxicity rates were lower with alectinib [26]. These impressive results await confirmation in the ALEX phase III trial, of larger sample size and including Caucasian patients (NCT02075840). In addition, studies comparing ceritinib to platinum-based chemotherapy are fully recruited and results are expected soon (NCT01828099).

In any case, it should be emphasised here the incremental impact of all available therapies, including chemotherapy, in the overall outcome of patients whose current survival frequently exceeds 4 years. It is likely that in the future, in a context of expanding TKI alternatives with differing activity against ALK kinase variants, regardless the initial treatment given, subsequent therapies will be guided by the changing genotype of the tumour as a consequence of the pressure of prior treatments.

\section{ROS1 rearrangements}

ROS1 rearrangements are found in 1-2\% of NSCLCs. As in the case of EGFR mutations or ALK fusions, they are very rarely found in squamous cell carcinomas or smokers, and are more prevalent among the young and females. 11 ROS1 fusion variants have been described to date, CD71 being the most frequent $5^{\prime}$ fusion partner [31]. ROS1 and ALK kinases are pylogenetically close, and their rearrangements in lung cancer share common carcinogenic properties, clinical characteristics, certain therapeutic vulnerabilities and probably acquired resistance mechanisms. 
In line with this premise, the PROFILE 1001 trial was amended early to include an expansion cohort of ROS1-rearranged NSCLC patients $(\mathrm{n}=50)$. Crizotinib achieved an overall response rate of $72 \%$ and median 19.2-month PFS, with $85 \%$ OS at 12 months in this 50 patient cohort [31]. A lower median PFS (9.1 months) was reported in a small retrospective observational study (response rate 80\%), but again compared favourably with the results obtained with standard platinum-pemetrexed based chemotherapy (table 3) [33]. Crizotinib has been recently approved by FDA for these patients.

Clinical development of next-generation dual ALK and ROS1 inhibitors (lorlatinib, ceritinib, brigatinib and entrectinib) and other ROS1 inhibitors (cabozantinib and foretinib) is currently ongoing [31]. Among them, cabozantinib and lorlatinib have already demonstrated the ability to overcome crizotinib resistance in the clinic $[29,79]$. Of note, among the 12 patients with $\mathrm{ROS1}^{+}$tumours included in an ongoing phase I/II trial, lorlatinib achieved an objective response rate of $33 \%$ and $66 \%$ in crizotinib-pretreated and crizotinib-naïve patients, respectively (table 3) [29]. Similarly to that described in ALK-driven disease, the fact that ROS1 mutations confer nonoverlapping resistance to dual ALK and ROS1 inhibitors or ROS1-specific inhibitors opens the possibility to sequence different TKIs upon subsequent disease progressions [80].

\section{Emerging targets}

BRAF activating mutations

The prevalence of $B R A F$ kinase domain mutations in NSCLC is roughly $2-4 \%$ and half of the cases harbour non-V600E mutations, the drug sensitivity and biological properties of which are much less well known than those of V600E. There seems to be no distinct distribution according to smoking status, sex or age [34]. $B R A F$ activating mutations induce constitutive phosphorylation of downstream proteins of the RAS/RAF/ MEK/ERK mitogen-activated protein kinase pathway, promoting aberrant cell proliferation and survival.

Type I BRAF inhibitors (vemurafenib and dabrafenib) have demonstrated robust clinical activity in $B R A F$ V600E mutant NSCLCs in isolated case reports [81-84], retrospective series [85] and prospective basket [86] or histology-specific trials [35]. In the VE-BASKET trial, vemurafenib showed a response rate of $42 \%$ in previously treated NSCLC subjects $(\mathrm{n}=20)$. The median PFS was 7.3 months and a preliminary 12-month OS rate of $66 \%$ was reported [86]. Similar results have recently been published with dabrafenib monotherapy in the NSCLC histology-specific BRF113928 phase II trial ( $\mathrm{n}=84$, overall response rate 33\%) [35]. Importantly, as already seen in melanoma, the clinical efficacy with the combination of dabrafenib and the allosteric MEK1/2 inhibitor trametinib is higher as compared to dafrafenib monotherapy. Thus, in a total of 57 pre-treated patients included in an independent cohort of the BRF113928 phase II study, the overall response rate was 63\% (disease control rate 79\%) and the median PFS achieved was 9.7 months (table 3) [36]. The safety profile of these drugs was manageable and consistent with that in melanoma patients.

\section{Evolving targets}

De novo MET amplification and MET exon 14 alterations

Whereas the co-occurrence of MET amplification and MET mutations within exon 14 is relatively common in NSCLC (15-20\%), these are distinct oncogenic drivers [37, 39, 40]. Separately, they represent approximately $3-4 \%$ of NSCLCs. Importantly, MET exon 14 alterations have been found in up to $20-30 \%$ of sarcomatoid lung carcinomas [37, 39, 40]. Of note, both alterations seem more frequent among older lung cancer patients, with no apparent major differences according to smoking status or between adenocarcinomas versus squamous cell carcinomas [37, 41]. MET exon 14 alterations are not activating. Instead, they lead to decreased MET degradation (commonly but not exclusively through splice site mutations causing exon 14 skipping), resulting in sustained and constitutive MET signalling [39, 40].

Crizotinib has shown encouraging antitumor activity either in high MET-amplified or MET exon 14-altered NSCLCs within the subsequently expanded independent cohorts of the still ongoing PROFILE 1001 trial. The level of MET amplification seems critical to the benefit of MET TKIs. Thus, crizotinib showed objective responses in $67 \%$ of previously treated high MET (i.e. MET/CEP7 ratio $\geqslant 5$ ) amplified patients $(\mathrm{n}=14)$, but this activity dropped to $0 \%$ and $17 \%$ in low and intermediate $M E T$ amplified patients, respectively [38]. In addition, a 44\% response rate (disease control rate $>90 \%$ ) has been reported in the cohort of MET exon 14-altered tumours (table 3) [42]. Other MET TKIs, such as cabozantinib and capmatinib, had also shown evidence of strong activity in small series of patients harbouring MET exon 14 altered-tumours [39, 40, 41, 87]. These promising results have prompted the initiation of prospective trials testing several MET TKI inhibitors for MET-amplified and/or METex14 $4^{+}$patients (e.g. NCT02414139).

\section{RET rearrangements}

The prevalence of RET rearrangements in NSCLCs is roughly $1 \%$, increasing up to $2-3 \%$ in EGFR, $A L K$ and KRAS wild-type tumours $[43,44]$ and $16 \%$ in pan-negative, never-smoker lung adenocarcinomas [43]. 
Many RET TKIs are multikinase inhibitors already in clinical use, including vandetanib, cabozantinib, lenvatinib, sunitinib, sorafenib and alectinib. Cabozantinib, vandetanib and lenvatinib have shown objective response rates of $16-53 \%$ in small molecularly selected phase II studies including mostly highly pretreated patients (table 3). Disease stabilisation was a common feature with both drugs, and immature median PFS estimates ranged 4.7-7.3 months [45-48]. Interestingly, higher clinical activity was seen in vandetaninb-treated patients harbouring the CCDC6-RET fusion variant ( $\mathrm{n}=6$; response rate $83 \%$, median PFS of 8.3 months) [46]. Similarly remarkable efficacy has been reported in retrospective series or isolated case reports treated with a variety of off-label RET-targeting drugs $[44,88,89]$. Overall, the efficacy data are thus still too immature to select the RET inhibitor of preference, but as off-target toxicities are relatively common and vary among the different agents, this may be a relevant factor to consider the selected TKI for an individual patient.

\section{NTRK rearrangements}

NTRK genes encode the TrkA (NTRK1), TrkB (NTRK2) and TrkC (NTRK3) receptor tyrosine kinase proteins. NTRK1 fusions (e.g. NTRK1-MPRIP and NTRK1-CD74) [49] have been reported in 1\% of unselected NSCLC cohorts [50,51], rising up to $3-4 \%$ in patients who screened negative for other molecular alterations $[50,51]$. They are enriched in the adenocarcinoma population and are apparently more frequent among former or current smokers [50, 51].

Among the at least nine potent pan-Trk inhibitors in development [90], entrectinib is at a more advanced stage of clinical testing in NSCLC [91, 92]. All NSCLC patients harbouring NTRK1-fused tumours included in two parallel phase I trials (three out of three) showed major objective responses [92]. Notably, central nervous system responses in heavily pre-treated patients have been reported [51]. An ongoing phase II basket trial is actively recruiting patients (NCT02568267).

\section{HER2 aberrations}

HER2 gene amplifications and mainly kinase domain mutations represent potential but distinct molecular targets in lung adenocarcinomas. Little or no overlap between both alterations has been published [52, 53]. HER2-mutant NSCLCs share common clinical-pathological features with those of EGFR mutant cancers and are found in $\sim 2 \%$ of lung adenocarcinomas $[52,53]$. The most frequent mutations consist of in-frame insertions in exon $20[52,53]$.

Combination therapies with trastuzumab and chemotherapy have shown activity in retrospective European cohorts [54, 55], and isolated clinical cases harbouring HER2 kinase domain mutations [93-95]. The efficacy of single-agent pan-HER TKIs including afatinib, dacomitinib or neratinib in these patients is modest at best [52, 55-57]. Objective responses were reported in $12 \%$ of patients with HER2-mutant tumours, but none in HER2-amplified cancers, treated with afatinib within a small phase II trial $(\mathrm{n}=26)$, with modest 3- and 9-month median PFS and OS, respectively (table 3) [56]. What specific molecular context predicts responsiveness and the optimal treatment strategy (single agent TKIs versus trastuzumab with or without chemotherapy) for these patients is yet to be defined.

\section{Potential targets}

KRAS has been considered as a clinically difficult to inhibit, if not undruggable, target. More recently, direct inhibition of KRAS with allele-specific (G12C) allosteric covalent inhibitors interacting with the inactive GDP-RAS state have shown potent RAS signalling inhibition in vitro [96, 97]. Inhibition of "downstream" proteins and synthetic lethality approaches are being actively pursued in clinical trials. The combination of docetaxel plus selumetinib, an allosteric MEK inhibitor, showed a significant improvement in response rates (37\% versus $0 \%$ ) and PFS (5.3 versus 2.1 months) when compared to docetaxel alone in a small phase II study [98], but this treatment finally failed to improve outcomes in a recently reported phase III trial [99]. Furthermore, it was associated with substantial toxicity, mainly haematological. However, CDK4 inhibition has been shown to be synthetically lethal in KRAS-mutant lung adenocarcinoma mouse models [100]. Disease control rate appeared superior in KRAS-mutant (55.2\%) compared to KRAS wild-type (37.5\%) NSCLCs treated with abemaciclib (CDK4/6 inhibitor) in a phase I trial [101]. A phase III trial of abemaciclib compared to erlotinib as second/third-line therapy is currently ongoing (NCT02152631).

The attempts to target aberrant FGFR [102], DDR2 [103] or PI3K [104] pathway activation have been clinically disappointing. More preclinical and clinical research is needed before they can be considered reliable predictive targets in this disease.

\section{Biological therapies for mostly molecularly unselected patients Antiangiogenics}

Bevacizumab, ramucirumab and nintedanib prolong survival in clinically selected candidates for antiangiogenic therapies when combined with chemotherapy. Data from a large meta-analysis confirmed the benefits of 
adding bevacizumab to first-line platinum based chemotherapy (HR for OS 0.90, 95\% CI 0.81-0.99; p=0.03) [105]. However, the combination of bevacizumab plus weekly paclitaxel is superior to standard second-line docetaxel in terms of response rates (22.5\% versus $5.5 \%, \mathrm{p}=0.006)$ and PFS (HR 0.62, $\mathrm{p}=0.005$ ), and thus may constitute another treatment option in this setting [106]. Its use is restricted to nonsquamous histology due to safety concerns (pulmonary haemorrhage in squamous cell cancers). Both ramucirumab and nintedanib numerically increased median PFS and OS by about 1 month and 1.5-2 months respectively when added to second-line docetaxel in phase III studies $[107,108]$. Nintedanib's OS benefit was restricted to nonsquamous histology (HR 0.83, 95\% CI 0.70-0.99; $\mathrm{p}=0.03$ ) and seemed more profound in platinum-refractory subsets [107]. Nintedanib is EMA, but not FDA, approved. The benefit of ramucirumab was independent of histology (HR 0.86, 95\% CI 0.75-0.98; $\mathrm{p}=0.02$ ) and it is the only antiangiogenic agent approved for squamous cell lung cancer patients [108]. An excess of predominantly low-grade toxicities related to antiangiogenic therapy (hypertension, proteinuria, and haemorrhagic or thrombotic events) were noted with bevacizumab and ramucirumab $[108,109]$. Bevacizumab and ramucirumab but not nintedanib (predominantly gastrointestinal and hepatic toxicities) increased the rates of neutropenia and febrile neutropenia [107-109].

\section{Anti-EGFR monoclonal antibodies}

Cetuximab and necitumumab are the two monoclonal antibodies targeting the extracellular domain of EGFR that have been most extensively studied in NSCLC. The addition of necitumumab to cisplatin and gemcitabine modestly improved OS, as compared to chemotherapy alone, in squamous cell cancers (11.5 versus 9.9 months; HR 0.84 , 95\% CI 0.74-0.96; $\mathrm{p}=0.012$ ), results that are consistent with those observed with cetuximab [110]. No benefit was observed in a nonsquamous NSCLC trial in combination with cisplatin and pemetrexed [111]. Skin rash, diarrhoea and hypomagnesaemia were significantly increased in the combination arm, with no excess of febrile neutropenia or thromboembolic events [110]. The drug is approved for unselected squamous cell cancers by the FDA, but only EGFR ${ }^{+}$cases according to EMA.

\section{Immunotherapy}

Innate and adaptive immune responses can recognise and kill cancer cells. Dendritic cells, macrophages, neutrophils and natural killer cells are critical to innate immunity, mediating early antigen-nonspecific immune responses by a limited number of receptors (e.g. Toll-like receptors). By contrast, adaptive immunity is mediated by T-cells $\left(\mathrm{CD}^{+}\right.$and $\left.\mathrm{CD}^{+}\right)$and $\mathrm{B}$-cells, and induces a robust, antigen-specific immune response [112]. There is solid evidence that demonstrates the existence of anti-tumour adaptive T-cell mediated immunity activation in established lung tumours, indicating that lung cancers are immunogenic [113,114]. As an example supporting this concept, increased levels of clonal tumour infiltrating $\mathrm{CD}^{+}$lymphocytes are independent predictors for favorable survival in lung cancer [115]. The reason why these tumours still evolve is precisely because cancer cells develop immune escape mechanisms and proliferate even in the presence of competent immune systems.

Immunotherapy against cancer can be classified as active or passive. Active immunotherapies rely on the activation of the host's own T-cell based anti-tumour responses. Contrary, passive immunotherapies retain intrinsic anti-tumour immunity. Two active immune-based therapies accumulate the majority of the clinical evidence in lung cancer: cancer vaccines and checkpoint inhibitors.

\section{Cancer vaccines}

Monovalent vaccines have failed to demonstrate robust survival benefits in randomised phase III trials [116-118], probably due to an insufficient T-cell immunity activation to overcome the immunosuppressive tumour microenvironment [119]. Treatment combinations with drugs reversing these immunosuppressive networks (e.g. checkpoint inhibitors) and/or novel potent formulations based on polyvalent vaccines might be promising strategies for the success of tumour vaccines in the future [120].

Immune checkpoint inhibitors: PD-1/PD-L1 pathway blockade

Among the multiple immune suppressive mechanisms that are generated within the tumour microenvironment, tumour cell induced dysregulation of immune checkpoint proteins has revealed as a major mechanism of anti-tumour T-cell immunity inhibition [121]. Upon activation, T-cells up-regulate a number or surface proteins that, in the presence of their ligands, modulate their activity either in an inhibitory (e.g. B- and T-lymphocyte attenuator (BTLA), inducible T-cell co-stimualtor, programmed death (PD)-1 and cytotoxic T-lymphocyte-associated 4 (CTLA4)) or stimulatory (e.g. OX40, CD40 and CD137) fashion [122]. Among them, CTLA4 and PD-1 are the two main regulators of T-cell activity, at least with respect to their clinical relevance in cancer. PD-1 is up-regulated on a great proportion of tumour-infiltrating lymphocytes, and its two major ligands, PD-L1 and PD-L2, are commonly overexpressed on the surface of tumour cells. This interaction results in an effective inhibition of the effector T-cell response. In contrast, binding of CTLA4 with its two major ligands CD80 and CD86 
(mainly expressed in antigen-presenting cells) preferentially modulates T-cell activation and expansion in lymph nodes [123]. Importantly, blocking these co-inhibitory signals, particularly the PD-1/PD-L1 interaction, has changed treatment paradigms of lung cancer.

Agonistic monoclonal antibodies targeting the co-inhibitory PD-1/PD-L1 interaction have recently impacted the treatment landscape of advanced NSCLC. Five drugs accumulate the vast majority of the clinical evidence to date: two anti PD-1 monoclonal antibodies (nivolumab and pembrolizumab) and three anti-PD-L1 monoclonal antibodies (atezolizumab, durvalumab and avelumab). Both safety and early activity seem similar with either PD-1 or PD-L1 blockade. Efficacy data from the initial phase I trial of nivolumab [124] have been confirmed in five large randomised trials for nivolumab, pembrolizumab and atezolizumab in pre-treated patients so far [125-129]. Consistent conclusions can be drawn regarding the efficacy of these drugs in unselected patients $[125,126,128,129]$ (table 4). First, the overall response rate is $\sim 20 \%$ and responses, which are usually detected early ( 2 months), are profound and durable (median 15 months versus 6 months with docetaxel). In addition, a substantial proportion of patients also achieve long-lasting disease stabilisation with clinical benefits. Second, median PFS ( $\sim 4$ months) probably does not capture the true benefit of these drugs either. Finally, PD-1/PD-L1 blockers robustly demonstrate a median $\sim 3$-month improvement in OS compared to second-line chemotherapy. Remarkably, about $15-20 \%$ of the patients treated with these drugs appear to survive for $>24$ months [125-129] (table 4), although longer follow-up is required to more definitively conclude on the potential for long-term survival. The toxicity profile also favours anti-PD-1/ PD-L1 therapy over chemotherapy, despite longer treatment exposures. The most frequently reported adverse event under PD-1 pathway blockade is asthenia (15-20\%), commonly a tumour-related symptom. Immune-related adverse events can be relatively common ( 20\%), but are mostly mild $(>90 \%)$ and rarely motivate drug withdrawal $(<5 \%)$. These toxicities typically involve the skin (erythema and rash), gastrointestinal tract (colitis and diarrhoea), endocrine glands (hypophisitis, thyroiditis and adrenalitis), liver (hepatitis) and lungs (pneumonitis). Although rare $(\sim 1-4 \%)$, special attention is merited by interstitial pneumonitis in lung cancer patients. To date, nivolumab has obtained regulatory approval (FDA and EMA) for NSCLCs progressing on first-line chemotherapy. Pembrolizumab is FDA approved in second or further lines of treatment for PD-L1 positive ( $\geqslant 1 \%$ of cells) NSCLCs. Atezolizumab has been also recently approved by the FDA for NSCLC patients progressing on platinum-containing chemotherapy.

Very recently, data from two large randomised phase III trials in the front-line setting have been reported $[130,131]$ (table 5). In one of these trials, pembrolizumab showed superior clinical activity to platinum-based doublet chemotherapy in terms of response rates (44.8\% versus $27.8 \%$ ), PFS (10.3 versus 6 months; HR 0.50 , $\mathrm{p}<0.001$ ) and OS (HR 0.60, p=0.005) among EGFR and ALK wild-type NSCLCs with PD-L1 expression on at least $50 \%$ of tumour cells [130]. These are practice-changing results, and might lead to a change in the standard of care of advanced-stage NSCLC. Other randomised trials against first-line platinum-based chemotherapy (e.g. NCT02477826) or studies assessing their role in earlier stages of the disease (e.g. adjuvant setting; NCT02595944, NCT02504372, NCT02486718 and NCT02273375) are already ongoing.

Several potential predictive biomarkers for optimal patient selection for anti-PD-1/PD-L1 therapy are actively being investigated. Among them, PD-L1 expression measured by immunohistochemistry, albeit not without some limitations that are out of the scope of this review, is the most feasible and applicable to the clinic at present. Its potential predictive role has been assessed in most of the randomised controlled trials (table 4). At least two studies in pre-treated patients that have enrolled PD-L1 ${ }^{-}$NSCLCs demonstrate a positive predictive role for PD-L1 expression, showing marked survival improvements for nivolumab compared to docetaxel among PD-L1 ${ }^{+}$NSCLCs (14.9-15.5 months with nivolumab compared to 8.29.2 months with docetaxel; HR $\sim 0.60)$ but overlapping survival curves in PD-L1 ${ }^{-}$subsets ( 9 months; HR 1) $[126,128]$. Conversely, in the OAK study, the OS improvement of atezolizumab over docetaxel was also observed in PD- $1^{-}$tumours, with a similar degree of benefit as in PD-L1 ${ }^{+}$NSCLC (HR 0.75, 95\% CI 0.59-0.96; $\mathrm{p}=0.02$ ) [129] (table 4). However, issues related to a potentially lower analytical performance of the SP142 clone used in this trial with respect to labelling percentages of PD-L1 ${ }^{+}$tumour-cells might limit the interpretation of these data [133]. Furthermore, among PD-L1 ${ }^{-}$NSCLCs, response rates and PFS seem somewhat consistently higher for docetaxel (10-15\% and 3.6-4.1 months, respectively) compared to anti-PD-1/PD-L1 drugs (8-9\% and 1.7-2.6 months, repectively) [126, 128, 129] (table 4). Notably, this predictability might be different for nonsquamous and squamous cell lung cancers, as at least in the relatively small cohort of squamous cell lung cancer patients enrolled in the CheckMate 017 trial, treatment benefits in terms of response rates, PFS and overall were superior for nivolumab compared to docetaxel, irrespective of PD-L1 expression [125] (table 4). In any case, what randomised trials reported to date almost invariably show is that treatment benefits with these drugs are proportional to the grade of expression, that is, response rates and survival tend to increase with increasing levels of tumour cell PD-L1 positivity (less studied for immune cell PD-L1) [126-131, 134]. For instance, those patients with $\geqslant 50 \%$ of tumour cell PD-L1 positivity, objective responses reached 45\% [134], and median OS in pre-treated 
TABLE 4 Practice-changing randomised trials with anti-PD-1/PD-L1 drugs in advanced, pre-treated (second-line) nonsmall cell lung cancer (NSCLC) patients

\begin{tabular}{|c|c|c|c|c|c|c|c|c|c|c|c|c|c|c|c|}
\hline \multirow[t]{2}{*}{ Trial } & \multirow[t]{2}{*}{ Subjects } & \multirow[t]{2}{*}{ Histology } & \multicolumn{3}{|c|}{ PD-L1 expression } & \multirow[t]{2}{*}{ Therapy } & \multicolumn{3}{|c|}{ RR } & \multicolumn{3}{|c|}{ mPFS months } & \multicolumn{3}{|c|}{ mOS months } \\
\hline & & & Selection & Positivity & Test/clone & & All & PD-L1+ & PD-L1 ${ }^{-}$ & All & ${\mathrm{PD}-\mathrm{L1}^{+}}^{+}$ & PD-L1- & All & PD-L1+ & ${\mathrm{PD}-\mathrm{L1}^{-}}^{-}$ \\
\hline $\begin{array}{c}\text { CheckMate } 017 \\
\text { (phase III] } \\
\text { [125] }\end{array}$ & 272 & SCC & No & $\geqslant 1 \%$ & Dako/28-8 & $\begin{array}{l}\text { Docetaxel } \\
\text { Nivolumab }\end{array}$ & $\begin{array}{l}9 \% \\
20 \%\end{array}$ & $\begin{array}{l}11 \% \\
17 \%\end{array}$ & $\begin{array}{l}10 \% \\
17 \%\end{array}$ & $\begin{array}{c}2.8 \\
3.5 \text { (HR 0.62) }\end{array}$ & $\begin{array}{c}2.8 \\
3.3(H R \\
0.67)\end{array}$ & $\begin{array}{c}3 \\
3.1(H R \\
0.66)\end{array}$ & $\begin{array}{c}6 \\
9.2(\mathrm{HR} \\
0.59)\end{array}$ & $\begin{array}{c}7.2 \\
9.3(H R \\
0.69)\end{array}$ & $\begin{array}{c}5.9 \\
8.7(\mathrm{HR} \\
0.58)\end{array}$ \\
\hline $\begin{array}{l}\text { CheckMate } 057 \\
\text { (phase III) } \\
\text { [126] }\end{array}$ & 582 & Non-SCC & No & $\geqslant 1 \%$ & Dako/28-8 & $\begin{array}{l}\text { Docetaxel } \\
\text { Nivolumab }\end{array}$ & $\begin{array}{l}12 \% \\
19 \%\end{array}$ & $\begin{array}{l}12 \% \\
31 \%\end{array}$ & $\begin{array}{l}15 \% \\
9 \%\end{array}$ & $\begin{array}{c}4.2 \\
2.3(H R \quad 0.92)\end{array}$ & $\begin{array}{c}4.5 \\
4.2(\mathrm{HR} \\
0.7)\end{array}$ & $\begin{array}{l}3.6 \\
2.1(H R \\
1.19)\end{array}$ & $\begin{array}{c}9.4 \\
12.2(\mathrm{HR} \\
0.73)\end{array}$ & $\begin{array}{c}9 \\
17.7 \\
(\mathrm{HR} \\
0.58)\end{array}$ & $\begin{array}{c}10.1 \\
10.5(H R \\
0.87)\end{array}$ \\
\hline $\begin{array}{l}\text { KEYNOTE-010 } \\
\text { (phase III) } \\
\text { [127] }\end{array}$ & 1034 & NSCLC & $\begin{array}{l}\text { Yes } \\
(\geqslant 1 \%)\end{array}$ & $\geqslant 1 \%$ & Dako/22C3 & $\begin{array}{c}\text { Docetaxel } \\
\text { Pembrolizumab } \\
2 \mathrm{mg} \cdot \mathrm{kg}^{-1}\end{array}$ & $\begin{array}{c}9 \% \\
18 \%\end{array}$ & $\begin{array}{c}8 \% \\
30 \%\end{array}$ & & $\begin{array}{c}4 \\
3.9 \text { (HR 0.88) }\end{array}$ & $\begin{array}{c}4.1 \\
5(\mathrm{HR} \\
0.59)\end{array}$ & & $\begin{array}{c}8.5 \\
10.4(H R \\
0.71)\end{array}$ & $\begin{array}{l}8.2 \\
14.9 \\
(\mathrm{HR} \\
0.54)\end{array}$ & \\
\hline & & & & & & $\begin{array}{l}\text { Pembrolizumab } \\
10 \mathrm{mg} \cdot \mathrm{kg}^{-1}\end{array}$ & $19 \%$ & $29 \%$ & & 4 (HR 0.79) & $\begin{array}{l}5.2(\mathrm{HR} \\
0.59)\end{array}$ & & $\begin{array}{c}12.7 \text { (HR } \\
0.61)\end{array}$ & $\begin{array}{l}17.3 \\
(\mathrm{HR} \\
0.50)\end{array}$ & \\
\hline $\begin{array}{l}\text { POPLAR (phase } \\
\text { II) [128] }\end{array}$ & 287 & NSCLC & No & $\begin{array}{l}\text { TC1-3 or } \\
\text { IC1-3 }\end{array}$ & $\begin{array}{l}\text { VENTANA/ } \\
\text { SP142 }\end{array}$ & $\begin{array}{c}\text { Docetaxel } \\
\text { Atezolizumab }\end{array}$ & $\begin{array}{l}15 \% \\
15 \%\end{array}$ & $\begin{array}{l}16 \% \\
18 \%\end{array}$ & $\begin{array}{l}10 \% \\
8 \%\end{array}$ & $\begin{array}{c}3 \\
2.7(H R \text { 0.94) }\end{array}$ & $\begin{array}{c}3 \\
2.8(H R \\
0.85)\end{array}$ & $\begin{array}{c}4.1 \\
1.7(\mathrm{HR} \\
1.12)\end{array}$ & $\begin{array}{c}9.7 \\
12.6(\mathrm{HR} \\
0.73)\end{array}$ & $\begin{array}{c}9.2 \\
15.5 \\
(H R \\
0.59)\end{array}$ & $\begin{array}{c}9.7 \\
9.7(H R \\
1.04)\end{array}$ \\
\hline $\begin{array}{l}\text { OAK (phase III] } \\
\text { [129] }\end{array}$ & 850 & NSCLC & No & $\begin{array}{l}\text { TC1-3 or } \\
\text { IC1-3 }\end{array}$ & $\begin{array}{l}\text { VENTANA/ } \\
\text { SP142 }\end{array}$ & $\begin{array}{c}\text { Docetaxel } \\
\text { Atezolizumab }\end{array}$ & $\begin{array}{l}13 \% \\
13 \%\end{array}$ & $\begin{array}{l}16 \% \\
18 \%\end{array}$ & $\begin{array}{l}11 \% \\
8 \%\end{array}$ & $\begin{array}{c}4 \\
2.8(H R \text { 0.95) }\end{array}$ & $\begin{array}{c}4.1 \\
2.8(H R \\
0.91)\end{array}$ & $\begin{array}{l}4 \\
2.6(H R \\
1)\end{array}$ & $\begin{array}{c}9.6 \\
13.8 \text { (HR } \\
0.73)\end{array}$ & $\begin{array}{l}10.3 \\
15.7 \\
(H R \\
0.74)\end{array}$ & $\begin{array}{c}8.9 \\
12.6 \text { (HR } \\
0.75)\end{array}$ \\
\hline
\end{tabular}

PD-L1+ data from KEYNOTE-010 refer to patients with at least $50 \%$ tumour-cell positivity; hazard ratio (HRs) take nivolumab as reference. RR: response rate; mPFS: median progression-free survival; mOS: median overall survival; SCC: squamous cell carcinoma. Italics indicate statistically nonsignificant results. 
TABLE 5 Randomised trials with anti-PD-1/PD-L1 drugs in advanced, previously untreated nonsmall cell lung cancer (NSCLC) patients

\begin{tabular}{|c|c|c|c|c|c|c|c|c|c|c|c|c|c|c|c|}
\hline \multirow[t]{2}{*}{ Trial } & \multirow[t]{2}{*}{ Subjects } & \multirow[t]{2}{*}{ Histology } & \multicolumn{3}{|c|}{ PD-L1 expression } & \multirow[t]{2}{*}{ Therapy } & \multicolumn{3}{|c|}{ RR } & \multicolumn{3}{|c|}{ mPFS months } & \multicolumn{3}{|c|}{ mOS months } \\
\hline & & & Selection & Positivity & Test/clone & & All & $\mathrm{PD}^{-\mathrm{L}^{+}}{ }^{+}$ & PD-L1- & All & PD-L1+ & PD-L1- & All & PD-L1+ & PD-L1 ${ }^{-}$ \\
\hline $\begin{array}{l}\text { KEYNOTE-024 } \\
\text { (phase III) } \\
\text { [130] }\end{array}$ & 305 & NSCLC & $\begin{array}{c}\text { Yes } \\
l \geqslant 50 \%)\end{array}$ & $\geqslant 50 \%$ & Dako/22C3 & $\begin{array}{l}\text { Platinum doublet } \\
\text { Pembrolizumab }\end{array}$ & $\begin{array}{l}27.8 \% \\
44.8 \%\end{array}$ & & & $\begin{array}{c}6 \\
10.3 \\
(\mathrm{HR} \\
0.50)\end{array}$ & & & $\begin{array}{l}\text { NR } \\
\text { NR } \\
\text { (HR } \\
0.60)\end{array}$ & & \\
\hline $\begin{array}{l}\text { CheckMate } \\
026 \text { (phase } \\
\text { III) [131] }\end{array}$ & 541 & NSCLC & $\begin{array}{l}\text { Yes } \\
(\geqslant 1 \%)\end{array}$ & $\geqslant 1-5 \%$ & Dako/28-8 & $\begin{array}{l}\text { Platinum doublet } \\
\text { Nivolumab }\end{array}$ & $\begin{array}{l}33.5 \% \\
26.1 \%\end{array}$ & & & $\begin{array}{l}5.9 \\
4.2 \\
(H R \\
1.15)\end{array}$ & $\begin{array}{l}(H R \\
1.07)\end{array}$ & & $\begin{array}{l}13.2 \\
14.4 \\
(H R \\
1.02)\end{array}$ & $\begin{array}{l}(H R \\
0.90)\end{array}$ & \\
\hline $\begin{array}{l}\text { KEYNOTE-021 } \\
\text { (phase II) } \\
\text { [132] }\end{array}$ & 123 & Non-SCC & No & $\geqslant 1-50 \%$ & Dako/22C3 & $\begin{array}{c}\text { Carboplatin } \\
\text { +pemetrexed } \\
\text { Carboplatin } \\
\text { +pemetrexed } \\
\text { +pembroliozumab }\end{array}$ & $\begin{array}{l}29 \% \\
55 \%\end{array}$ & $\begin{array}{l}35 \% \\
80 \%\end{array}$ & $\begin{array}{l}13 \% \\
57 \%\end{array}$ & $\begin{array}{c}8.9 \\
\\
13 \\
(\mathrm{HR} \\
0.53)\end{array}$ & & & $\begin{array}{l}\text { NR } \\
N R\end{array}$ & & \\
\hline
\end{tabular}

PD-L1 ${ }^{+}$data from CheckMate 026 and KEYNOTE-021 trials refer to patients with at least $50 \%$ of tumour-cell positivity; hazard ratios (HRs) data take nivolumab as reference. RR: response rate; mPFS: median progression-free survival; mOS: median overall survival; NR: not reached; SCC: squamous cell carcinoma. Italics indicate statistically nonsignificant results. 
patients was $\geqslant 17.2$ months in the biomarker selected KEYNOTE-001 and KEYNOTE-010 trials $[127,134]$ ( $\sim 9$ months with docetaxel) (table 4 ). Furthermore, anti-PD-1 inhibitors showed superiority against first-line platinum-based chemotherapy in NSCLCs with $\geqslant 50 \%$ of tumour PD-L1 positivity [130] but not among those with $\geqslant 5 \%$ PD-L1 positivity (HR for PFS 1.15, p=0.25) [131] (table 5). Somewhat surprisingly, in the small cohort of $\geqslant 50 \%$ PD-L1 ${ }^{+}$NSCLC in this trial, nivolumab did not demonstrate superiority either [131]. These results are inconsistent with other nivolumab trial data [135] and should be cautiously interpreted.

Although it is a challenging issue to address in the clinic, not only the quantity but also the context in which PD-L1 is expressed should be taken into consideration. Thus, PD-L1 might be intrinsically overexpressed as a result of the activation of aberrant oncogenic pathways or induced upon interferon (IFN)- $\gamma$ release as a mechanism of anti-tumour T-cell immune evasion (adaptive immune resistance). Accumulating evidence does suggest that the latter is more relevant and probably needed in order to obtain a response with anti-PD-1/PD-L1 drugs $[136,137]$. In fact, other surrogates of pre-existing immunity such as high tumour mutational load [138], presence of clonal tumour infiltrating lymphocytes [139] and Th1-type or IFN-based transcriptomic signatures [140] have shown to be positive predictive markers for the benefit from these drugs [137].

Treatment outcomes seem largely independent from histology [125-128]. With regard to other clinical or molecular markers analysed, smokers (HR 0.70 versus HR 1.02 in never-smokers), EGFR wild-type (HR 0.66 versus HR 1.18 in EGFR-mutant tumours) and KRAS-mutant lung adenocarcinomas (HR 0.52 versus HR 0.98 in KRAS wild-type tumours), that is, tumour subtypes that are normally associated with higher mutational burden tend to derive greater treatment benefits from anti-PD-1/PD-L1 drugs [126].

Combinatorial therapies with PD-1 pathway blockade

For PD-1/PD-L1 blockade, combination strategies incorporate another treatment modality aiming to generate or enhance a stronger anti-tumour T-cell immune response and/or reverse the immune-suppressive tumour microenvironment. Multiple clinical studies are ongoing in this field, testing combinatorial treatment strategies that include: immunogenic cancer cell death inducers (chemotherapy, radiotherapy, targeted therapy and oncolytic viruses); strategies to increase anti-tumour T-cell activation (anti-CTLA4 monocloncal antibodies and cancer vaccines); strategies to increase T-cell trafficking into tumours (e.g. epigenetic reprogramming drugs, cytokines and antiangiogenics); strategies to stimulate T-cell cytotoxic effects (e.g. monoclonal antibodies targeting co-stimulatory checkpoint proteins (e.g. CD137, CD40, OX40 and GITR); adoptive T-cell therapy; and drugs targeting other immunosuppressive tumour pathways (e.g. monocloncal antibodies targeting other co-inhibitory checkpoints (e.g. CTLA4, TIM3, LAG3, BTLA and TIGIT) or idoleamine-2,3-dioxigenase inhibitors) [137].

The combination of anti-PD-1/PD-L1 plus anti-CTLA4 blockade has already shown to be synergistic and highly active in metastasic melanoma [141]. Preliminary results from three phase I studies in NSCLC have also been reported. These trials show that toxicities are dose and schedule dependent, and might be severe in a significant proportion of patients $(17-50 \%)[135,142,143]$. The most updated efficacy outcomes come from the CheckMate 012 trial, where modified combination treatment schedules are being investigated in treatment-naïve, advanced NSCLC patients $(n=130)$. Again, treatment benefits were higher for patients with PD-L1 ${ }^{+}$tumours (pooled response rates 57\%; median PFS of 10.6 and 8.1 months, respectively) compared to PD-L1 ${ }^{-}$NSCLCs (pooled response rates $18 \%$; median PFS of 2.4 months and 4.7 months, respectively). Of note, efficacy was also higher, with increasing levels of PD-L1 expression $\left(\geqslant 50 \%\right.$ PD- $1_{1}^{+}$tumours: pooled response rates $92 \%$; median PFS $>12$ months; 1 -year OS rate $\left.90-100 \%\right)$. All these data compared favourably with the results obtained in the independent cohort of patients treated with nivolumab monotherapy and, at least for PD-L1 ${ }^{+}$NSCLCs, largely exceed the results expected with standard first-line platinum-based chemotherapy [135].

Immature efficacy data are also available for the combination of PD-1/PD-L1 inhibitors plus conventional anticancer therapies. In a recently published small phase II trial $(n=123)$, the combination of pembrolizumab plus carboplatin and pemetrexed significantly increased response rates (55\% versus 29\%) and median PFS (13 versus 8.9 months; HR 0.53, $\mathrm{p}=0.01$ ) compared to chemotherapy alone, with an acceptable toxicity profile [132] (table 5). A phase III trial testing this combination is currently ongoing (NCT02578680). Remarkable response rates (30-75\%) have been reported with other anti-PD-1/PD-L1 drugs plus platinum-based first-line chemotherapy in several phase I trials [144-146]. Multiple studies are also in progress testing the combination of checkpoint inhibitors plus oncogene-targeted therapies in molecularly selected patients (e.g. NCT02013219 and NCT02584634).

\section{Conclusions and future perspectives}

Biological therapies, particularly genotype-tailored treatments and immune checkpoint inhibitors, have improved treatment outcomes of a substantial proportion of NSCLC patients. At present, the selection of 
these treatments is based on several predictive biomarkers that are tested in tumour specimens, underscoring the need for a multidisciplinary management of these patients for prompt diagnosis, tissue collection and sample priorisitation. Importantly, the development of novel technologies for detecting circulating tumour biomarkers (e.g. free serum tumour DNA genotyping methods) is rapidly evolving [147]. These technologies will be particularly useful when there is limited access to tumour biopsies, and will surely constitute important complementary sources of tumour material for genomic, molecular and immune-profiling analysis in the near future [3].

As the complexity and number of targetable genomic events increases, optimisation of molecular profiling technologies for the clinic and conducting innovative biomarker-driven clinical trials are needed for the success of precision oncology and novel genotype-tailored drug development. In addition, in order to achieve long-term survival benefits in oncogene-selected patients, understanding the sources of tumour heterogeneity and acquired resistance with continuous tumour monitoring and post-progression tumour genotyping is needed. This approach has important clinical limitations, as serial re-biopsies are not always feasible in the clinic and not free from risk in some cases. Clinical validation of plasma genotyping methods will be very important in this context in the upcoming years. Combinatorial therapies instead of sequential treatments might be another way to delay aggressive forms of resistance and positively impact treatment outcomes in this regard.

The recent success of immune therapies in lung cancer underscores the importance of profiling and targeting the tumour microenvironment as well. Development of novel immune-based treatments is exponentially expanding, and treatment combinations on the pillar of therapies reversing tumour immune-suppression (e.g. PD-1 blockade plus conventional cancer therapies or other immune approaches) are promising future strategies for NSCLC patients. The integration of immunobiologists into the multidisciplinary teams will be necessary in the near future in order to select for the potentially most effective and less toxic combinations, and a close multidisciplinary collaboration with other medical disciplines will be paramount to prevent and early treatment of immune-related adverse events.

\section{References}

Siegel RL, Miller KD, Jemal A. Cancer statistics, 2016. CA Cancer J Clin 2016; 66: 7-30.

Herbst RS, Heymach JV, Lippman SM. Lung cancer. N Engl J Med 2008; 359: 1367-1380.

Swanton C, Govindan R. Clinical implications of genomic discoveries in lung cancer. N Engl J Med 2016; 374: 1864-1873.

4 Conde E, Angulo B, Izquierdo E, et al. Lung adenocarcinoma in the era of targeted therapies: histological classification, sample prioritization, and predictive biomarkers. Clin Transl Oncol 2013; 15: 503-508.

5 Dietel M, Bubendorf L, Dingemans A-MC, et al. Diagnostic procedures for non-small-cell lung cancer (NSCLC): recommendations of the European Expert Group. Thorax 2016; 71: 177-184.

6 Devarakonda S, Morgensztern D, Govindan R. Genomic alterations in lung adenocarcinoma. Lancet Oncol 2015; 16: e342-e351.

7 Piotrowska Z, Sequist LV. Epidermal growth factor receptor-mutant lung cancer: new drugs, new resistance mechanisms, and future treatment options. Cancer J 2015; 21: 371-377.

8 Yang J, Ramalingam S, Janne PA, et al. Osimertinib (AZD9291) in pre-treated pts with T790M-positive advanced NSCLC: updated phase 1 (P1) and pooled phase 2 (P2) results. J Thorac Oncol 2016; 11: Suppl., S152-S153.

9 Ramalingam S, Yang J, Lee CK, et al. Osimertinib as first-line treatment for EGFR mutation-positive advanced NSCLC: updated efficacy and safety results from two phase I expansion cohorts. J Thorac Oncol 2016; 11: Suppl., S152.

10 Sequist LV, Soria J-C, Camidge DR. Update to rociletinib data with the RECIST confirmed response rate. $N$ Engl J Med 2016; 374: 2296-2297.

11 Park K, Lee JS, Lee KH, et al. BI 1482694 (HM61713), an EGFR mutant-specific inhibitor, in T790M ${ }^{+}$NSCLC: efficacy and safety at the RP2D. J Clin Oncol 2016; 34: Suppl., abstr 9055.

12 Tan DS, Yang JC, Leighl NB, et al. Updated results of a phase 1 study of EGF816, a third-generation, mutant-selective EGFR tyrosine kinase inhibitor (TKI), in advanced non-small cell lung cancer (NSCLC) harboring T790M. J Clin Oncol 2016; 34: Suppl., abstr 9044.

13 Yu HA, Spira AI, Horn L, et al. Antitumor activity of ASP8273 $300 \mathrm{mg}$ in subjects with EGFR mutation-positive non-small cell lung cancer: Interim results from an ongoing phase 1 study. J Clin Oncol 2016; 34: Suppl., abstr 9050.

14 Goto Y, Nokihara H, Murakami H, et al. ASP8273, a mutant-selective irreversible EGFR inhibitor in patients (pts) with NSCLC harboring EGFR activating mutations: Preliminary results of first-in-human phase I study in Japan. J Clin Oncol 2015; 33: Suppl., abstr 8014.

15 Hallberg B, Palmer RH. Mechanistic insight into ALK receptor tyrosine kinase in human cancer biology. Nat Rev Cancer 2013; 13: 685-700.

16 Kwak EL, Bang Y-J, Camidge DR, et al. Anaplastic lymphoma kinase inhibition in non-small-cell lung cancer. N Engl J Med 2010; 363: 1693-1703.

17 Shaw AT, Kim D-W, Nakagawa K, et al. Crizotinib versus chemotherapy in advanced ALK-positive lung cancer. N Engl J Med 2013; 368: 2385-2394.

18 Solomon BJ, Mok T, Kim D-W, et al. First-line crizotinib versus chemotherapy in ALK-positive lung cancer. N Engl J Med 2014; 371: 2167-2177.

19 Kim D-W, Mehra R, Tan DSW, et al. Activity and safety of ceritinib in patients with ALK-rearranged non-small-cell lung cancer (ASCEND-1): updated results from the multicentre, open-label, phase 1 trial. Lancet Oncol 2016; 17: 452-463. 

chemotherapy and crizotinib (CRZ). J Clin Oncol 2015; 33: Suppl., abstr 8059.

21 Felip E, Orlov S, Park K, et al. Phase 2 study of ceritinib in ALKi-naïve patients (pts) with ALK-rearranged $\left(A L K^{+}\right)$non-small cell lung cancer (NSCLC): whole body responses in the overall pt group and in pts with baseline brain metastases (BM). Ann Oncol 2016; 27: Suppl. 6, $1208 \mathrm{O}$.

22 Scagliotti G, Kim T, Crino L, et al. Ceritinib vs chemotherapy (CT) in patients (pts) with advanced anaplastic lymphoma kinase $(A L K)$-rearranged $\left(A L K^{+}\right)$non-small cell lung cancer (NSCLC) previously treated with CT and crizotinib (CRZ): results from the confirmatory phase 3 ASCEND-5 study. Ann Oncol (Meeting Abstract) 2016; 27: Suppl. 6, LBA42_PR.

23 Shaw AT, Gandhi L, Gadgeel S, et al. Alectinib in ALK-positive, crizotinib-resistant, non-small-cell lung cancer: a single-group, multicentre, phase 2 trial. Lancet Oncol 2016; 17: 234-242.

24 Ou S-HI, Ahn JS, De Petris L, et al. Alectinib in crizotinib-refractory ALK-rearranged non-small-cell lung cancer: a phase II global study. J Clin Oncol 2016; 34: 661-668.

25 Seto T, Kiura K, Nishio M, et al. CH5424802 (RO5424802) for patients with ALK-rearranged advanced non-small-cell lung cancer (AF-001JP study): a single-arm, open-label, phase 1-2 study. Lancet Oncol 2013; 14: 590-598.

26 Nokihara $\mathrm{H}$, Hida T, Kondo $\mathrm{M}$, et al. Alectinib (ALC) versus crizotinib (CRZ) in ALK-inhibitor naive ALK-positive non-small cell lung cancer (ALK ${ }^{+}$NSCLC): Primary results from the J-ALEX study. J Clin Oncol 2015; 34: Suppl., abstr 9008.

27 Gettinger SN, Bazhenova LA, Langer CJ, et al. Activity and safety of brigatinib in ALK-rearranged non-small-cell lung cancer and other malignancies: a single-arm, open-label, phase 1/2 trial. Lancet Oncol 2016; 17: 1683-1696.

28 Kim DW, Tiseo M, Ahn MJ, et al. Brigatinib (BRG) in patients (pts) with crizotinib (CRZ)-refractory ALK non-small cell lung cancer (NSCLC): first report of efficacy and safety from a pivotal randomized phase (ph) 2 trial (ALTA). J Clin Oncol 2016; 34: Suppl., abstr 9007.

29 Solomon BJ, Bauer TM, Felip E, et al. Safety and efficacy of lorlatinib (PF-06463922) from the dose-escalation component of a study in patients with advanced $A L K^{+}$or $R_{O S 1^{+}}$non-small cell lung cancer (NSCLC). $J$ Clin Oncol 2016; 34: Suppl., abstr 9009.

30 Horn L, Wakelee H, Blumenschein G, et al. Phase I/II trial of X-396 in patients (pts) with $A L K^{+}$non-small cell lung cancer (NSCLC): correlation with plasma and tissue genotyping and response to therapy (tx). Ann Oncol 2016; 27: Suppl. 6, 1210PD.

31 Ye M, Zhang X, Li N, et al. ALK and ROS1 as targeted therapy paradigms and clinical implications to overcome crizotinib resistance. Oncotarget 2016; 7: 12289-12304.

32 Shaw AT, Ou S-HI, Bang Y-J, et al. Crizotinib in ROS1-rearranged non-small-cell lung cancer. N Engl J Med 2014; 371: 1963-1971.

33 Mazieres J, Zalcman G, Crinò L, et al. Crizotinib therapy for advanced lung adenocarcinoma and a ROS1 rearrangement: results from the EUROS1 cohort. J Clin Oncol 2015; 33: 992-999.

34 Nguyen-Ngoc T, Bouchaab H, Adjei AA, et al. BRAF alterations as therapeutic targets in non-small-cell lung cancer. J Thorac Oncol 2015; 10: 1396-1403.

35 Planchard D, Kim TM, Mazieres J, et al. Dabrafenib in patients with $\mathrm{BRAF}^{\mathrm{V} 600 \mathrm{E}}$-positive advanced non-small-cell lung cancer: a single-arm, multicentre, open-label, phase 2 trial. Lancet Oncol 2016; 17: 642-650

36 Planchard D, Besse B, Groen HJM, et al. Dabrafenib plus trametinib in patients with previously treated $B R A F^{\mathrm{V} 600 \mathrm{E}}$-mutant metastatic non-small cell lung cancer: an open-label, multicentre phase 2 trial. Lancet Oncol 2016; 17: 984-993.

37 Tong JH, Yeung SF, Chan AW, et al. MET amplification and exon 14 splice site mutation define unique molecular subgroups of non-small cell lung carcinoma with poor prognosis. Clin Cancer Res 2016; 22: 3048-3056.

38 Camidge R, Ou I, Shapiro G, et al. Efficacy and safety of crizotinib in patients with advanced $c$-MET-amplified non-small cell lung cancer (NSCLC). J Clin Oncol 2014; 32: Suppl., 5s.

39 Paik PK, Drilon A, Fan P-D, et al. Response to MET inhibitors in patients with stage IV lung adenocarcinomas harboring MET mutations causing exon 14 skipping. Cancer Discov 2015; 5: 842-849.

40 Frampton GM, Ali SM, Rosenzweig M, et al. Activation of MET via diverse exon 14 splicing alterations occurs in multiple tumor types and confers clinical sensitivity to MET inhibitors. Cancer Discov 2015; 5: 850-859.

41 Awad MM, Oxnard GR, Jackman DM, et al. MET exon 14 mutations in non-small-cell lung cancer are associated with advanced age and stage-dependent MET genomic amplification and c-Met overexpression. J Clin Oncol 2016; 34: 721-730.

42 Drilon A, Camidge R, Ou I, et al. Efficacy and safety of crizotinib in patients (pts) with advanced MET exon 14-altered non-small cell lung cancer (NSCLC). J Clin Oncol 2016; 34: Suppl., abstr 108.

43 Drilon A, Wang L, Hasanovic A, et al. Response to cabozantinib in patients with RET fusion-positive lung adenocarcinomas. Cancer Discov 2013; 3: 630-635.

44 Michels S, Scheel AH, Scheffler M, et al. Clinicopathological characteristics of RET rearranged lung cancer in European patients. J Thorac Oncol 2016; 11: 122-127.

45 Drilon A, Sima CS, Somwar R, et al. Phase II study of cabozantinib for patients with advanced RET-rearranged lung cancers. J Clin Oncol 2015; 33: Suppl., abstr 8007.

46 Seto T, Yoh K, Satouchi M, et al. A phase II open-label single-arm study of vandetanib in patients with advanced RET-rearranged non-small cell lung cancer (NSCLC): Luret study. J Clin Oncol 2016; 34: Suppl., abstr 9012.

47 Lee SH, Lee JK, Ahn MJ, et al. A phase II study of vandetanib in patients with non-small cell lung cancer harboring RET rearrangement. J Clin Oncol 2016; 34: Suppl., abstr 9013.

48 Velcheti V, Hida T, Reckamp KL, et al. Phase 2 study of lenvatinib (LN) in patients (Pts) with RET fusion-positive adenocarcinoma of the lung. Ann Oncol 2016; 27: Suppl. 6, 1204PD.

49 Vaishnavi A, Le AT, Doebele RC. TRKing down an old oncogene in a new era of targeted therapy. Cancer Discov 2015; 5: 25-34.

50 Vaishnavi A, Capelletti M, Le AT, et al. Oncogenic and drug-sensitive NTRK1 rearrangements in lung cancer. Nat Med 2013; 19: 1469-1472.

51 Farago AF, Le LP, Zheng Z, et al. Durable clinical response to entrectinib in NTRK1-rearranged non-small cell lung cancer. J Thorac Oncol 2015; 10: 1670-1674. 

2014; 9: 1750-1762.

53 Li BT, Ross DS, Aisner DL, et al. HER2 amplification and HER2 mutation are distinct molecular targets in lung cancers. J Thorac Oncol 2016; 11: 414-419.

54 Mazieres J, Peters S, Lepage B, et al. Lung cancer that harbors an HER2 mutation: epidemiologic characteristics and therapeutic perspectives. I Clin Oncol 2013; 31: 1997-2003.

55 Mazieres J, Barlesi F, Filleron T, et al. Lung cancer patients with HER2 mutations treated with chemotherapy and HER2-targeted drugs: results from the European EUHER2 cohort. Ann Oncol 2016; 27: 281-286.

56 Kris MG, Camidge DR, Giaccone G, et al. Targeting HER2 aberrations as actionable drivers in lung cancers: phase II trial of the pan-HER tyrosine kinase inhibitor dacomitinib in patients with HER2-mutant or amplified tumors. Ann Oncol 2015; 26: 1421-1427.

57 Besse B, Soria JC, Yao B, et al. Neratinib with or without temsirolimus in patients with non-small cell lung cancer (NSCLC) carrying HER2 somatic mutations: an international randomized phase II study. Ann Oncol 2014; 25: Suppl. 4, mdu438.47.

58 Cancer Genome Atlas Research Network. Comprehensive genomic characterization of squamous cell lung cancers. Nature 2012; 489: 519-525.

59 Gandara DR, Hammerman PS, Sos ML, et al. Squamous cell lung cancer: from tumor genomics to cancer therapeutics. Clin Cancer Res 2015; 21: 2236-2243.

60 Scaltriti M, Baselga J. The epidermal growth factor receptor pathway: a model for targeted therapy. Clin Cancer Res 2006; 12: 5268-5272.

61 Haaland B, Tan PS, de Castro G, et al. Meta-analysis of first-line therapies in advanced non-small-cell lung cancer harboring EGFR-activating mutations. J Thorac Oncol 2014; 9: 805-811.

62 Popat S, Mok T, Yang JC-H, et al. Afatinib in the treatment of EGFR mutation-positive NSCLC - a network meta-analysis. Lung Cancer 2014; 85: 230-238.

63 Park K, Tan EH, O’Byrne K, et al. Afatinib versus gefitinib as first-line treatment of patients with EGFR mutation-positive non-small-cell lung cancer (LUX-Lung 7): a phase 2B, open-label, randomised controlled trial. Lancet Oncol 2016; 17: 577-589.

64 Camidge DR, Pao W, Sequist LV. Acquired resistance to TKIs in solid tumours: learning from lung cancer. Nat Rev Clin Oncol 2014; 11: 473-481.

65 Jänne PA, Yang JC-H, Kim D-W, et al. AZD9291 in EGFR inhibitor-resistant non-small-cell lung cancer. N Engl J Med 2015; 372: 1689-1699.

66 Sequist LV, Soria J-C, Goldman JW, et al. Rociletinib in EGFR-mutated non-small-cell lung cancer. N Engl J Med 2015; 372: 1700-1709.

67 Thress KS, Paweletz CP, Felip E, et al. Acquired EGFR C797S mutation mediates resistance to AZD9291 in non-small cell lung cancer harboring EGFR T790M. Nat Med 2015; 21: 560-562.

68 Piotrowska Z, Niederst MJ, Karlovich CA, et al. Heterogeneity underlies the emergence of EGFR ${ }^{\text {T790 }}$ wild-type clones following treatment of T790M-positive cancers with a third-generation EGFR inhibitor. Cancer Discov 2015; 5: 713-722.

69 Jia Y, Yun C-H, Park E, et al. Overcoming $E G F R^{\mathrm{T} 790 \mathrm{M}}$ and $E G F R^{\mathrm{C} 797 \mathrm{~S}}$ resistance with mutant-selective allosteric inhibitors. Nature 2016; 534: 129-132.

70 Wu YL, Kim DW, Felip E, et al. Phase (Ph) II safety and efficacy results of a single-arm $\mathrm{Ph} \mathrm{Ib} / \mathrm{II}$ study of capmatinib (INC280) + gefitinib in patients (pts) with EGFR-mutated (mut), cMET-positive (cMET ${ }^{+}$) non-small cell lung cancer (NSCLC). J Clin Oncol 2016; 34: Suppl., abstr 9020.

71 Seto T, Kato T, Nishio M, et al. Erlotinib alone or with bevacizumab as first-line therapy in patients with advanced non-squamous non-small-cell lung cancer harbouring EGFR mutations (JO25567): an open-label, randomised, multicentre, phase 2 study. Lancet Oncol 2014; 15: 1236-1244.

72 Stahel R, Dafni U, Gautschi O, et al. A phase II trial of erlotinib (E) and bevacizumab (B) in patients with advanced non-small-cell Lung Cancer (NSCLC) with activating epidermal growth factor receptor (EGFR) mutations with and without T790M mutation. The Spanish Lung Cancer Group (SLCG) and the European Thoracic Oncology Platform (ETOP) BELIEF trial. Eur J Cancer (Meeting Abstract) 2015; 51: Suppl. 3, S711-S712.

73 Katayama R, Lovly CM, Shaw AT. Therapeutic targeting of anaplastic lymphoma kinase in lung cancer: a paradigm for precision cancer medicine. Clin Cancer Res 2015; 21: 2227-2235.

74 Park K, Tan D, Ahn MA, et al. Efficacy and safety of ceritinib in patients (pts) with $A L K$-rearranged (ALK ${ }^{+}$) non-small cell lung cancer (NSCLC) and baseline brain metastases (BM) - results from ASCEND-2 and ASCEND-3. Ann Oncol 2015; 26: Suppl. 9, 125-147.

75 Gadgeel S, Shaw A, Govindan R, et al. Pooled analysis of CNS response to alectinib in two studies of pre-treated ALK ${ }^{+}$NSCLC. J Thorac Oncol 2015; 10: Suppl. 2, S238.

76 Gainor JF, Dardaei L, Yoda S, et al. Molecular mechanisms of resistance to first- and second-generation ALK inhibitors in ALK-rearranged lung cancer. Cancer Discov 2016; 6: 1118-1133.

77 Politi K, Gettinger S. Perfect ALKemy: optimizing the use of ALK-directed therapies in lung cancer. Clin Cancer Res 2014; 20: 5576-5578.

78 Ohe Y, Nishio M, Kiura K, et al. A phase I/II study with a CNS-penetrant, selective ALK inhibitor alectinib in $A L K$-rearranged non-small cell lung cancer ( $A L K^{+}$NSCLC) patients (pts): updates on progression free survival (PFS) and safety results from AF-001JP. J Clin Oncol 2015; 33: Suppl., abstr 8061.

79 Drilon A, Somwar R, Wagner JP, et al. A novel crizotinib-resistant solvent-front mutation responsive to cabozantinib therapy in a patient with ROS1-rearranged lung cancer. Clin Cancer Res 2016; 22: 2351-2358.

80 Davare MA, Vellore NA, Wagner JP, et al. Structural insight into selectivity and resistance profiles of ROS1 tyrosine kinase inhibitors. Proc Natl Acad Sci USA 2015; 112: E5381-E5390.

81 Gautschi O, Pauli C, Strobel K, et al. A patient with BRAF V600E lung adenocarcinoma responding to vemurafenib. J Thorac Oncol 2012; 7: e23-e24.

82 Peters S, Michielin O, Zimmermann S. Dramatic response induced by vemurafenib in a BRAF V600E-mutated lung adenocarcinoma. J Clin Oncol 2013; 31: e341-e344.

83 Robinson SD, O'Shaughnessy JA, Cowey CL, et al. BRAF V600E-mutated lung adenocarcinoma with metastases to the brain responding to treatment with vemurafenib. Lung Cancer 2014; 85: 326-330. 
Myall NJ, Neal JW, Cho-Phan CD, et al. Long-term survival of a patient with non-small-cell lung cancer harboring a V600E mutation in the BRAF oncogene. Clin Lung Cancer 2016; 17: e17-e21.

Gautschi O, Milia J, Cabarrou B, et al. Targeted therapy for patients with BRAF-mutant lung cancer: results from the European EURAF Cohort. J Thorac Oncol 2015; 10: 1451-1457.

Hyman DM, Puzanov I, Subbiah V, et al. Vemurafenib in multiple nonmelanoma cancers with BRAF V600 mutations. N Engl J Med 2015; 373: 726-736.

Shea M, Huberman MS, Costa DB. Lazarus-type response to crizotinib in a patient with poor performance status and advanced MET exon 14 skipping mutation-positive lung adenocarcinoma. J Thorac Oncol 2016; 11: e81-e82.

Gautschi O, Zander T, Keller FA, et al. A patient with lung adenocarcinoma and RET fusion treated with vandetanib. J Thorac Oncol 2013; 8: e43-e44.

Gautschi O, Wolf J, Milia J, et al. Targeting RET in patients with RET-rearranged lung cancers: results from a global registry. J Clin Oncol 2016; 34: Suppl., abstr 9014.

Passiglia F, Caparica R, Giovannetti E, et al. The potential of neurotrophic tyrosine kinase (NTRK) inhibitors for treating lung cancer. Expert Opin Investig Drugs 2016; 25: 385-392.

Patel MR, Bauer TM, Liu SV, et al. Phase 1/2a study of entrectinib, an oral Pan-Trk, ROS1, and ALK inhibitor, in patients with advanced solid tumors with relevant molecular alterations. J Clin Oncol 2015; 33: Suppl., abstr 2596.

Siena S, Drilon A, Ou I, et al. Entrectinib (RXDX-101), an oral pan-Trk, ROS1, and ALK inhibitor in patients with advanced solid tumors harboring gene rearrangements. Eur J Cancer 2015; 51: Suppl. 3, S724-S725.

Cappuzzo F, Bemis L, Varella-Garcia M. HER2 mutation and response to trastuzumab therapy in non-small-cell lung cancer. N Engl J Med 2006; 354: 2619-2621.

Tomizawa K, Suda K, Onozato R, et al. Prognostic and predictive implications of HER2/ERBB2/neu gene mutations in lung cancers. Lung Cancer 2011; 74: 139-144.

Weiler D, Diebold J, Strobel K, et al. Rapid response to trastuzumab emtansine in a patient with HER2-driven lung cancer. J Thorac Oncol 2015; 10: e16-e17.

Patricelli MP, Janes MR, Li L-S, et al. Selective inhibition of oncogenic KRAS output with small molecules targeting the inactive state. Cancer Discov 2016; 6: 316-329.

Lito P, Solomon M, Li L-S, et al. Allele-specific inhibitors inactivate mutant KRAS G12C by a trapping mechanism. Science 2016; 351: 604-608.

Jänne PA, Shaw AT, Pereira JR, et al. Selumetinib plus docetaxel for KRAS-mutant advanced non-small-cell lung cancer: a randomised, multicentre, placebo-controlled, phase 2 study. Lancet Oncol 2013; 14: 38-47.

Janne PA, Van den Heuvel M, Barlesi F, et al. Selumetinib in combination with docetaxel as second-line treatment for patients with KRAS-mutant advanced NSCLC: results from the phase III SELECT-1 trial. Ann Oncol 2016; 27: Suppl. 6, LBA47_PR.

Puyol M, Martín A, Dubus P, et al. A synthetic lethal interaction between K-Ras oncogenes and Cdk4 unveils a therapeutic strategy for non-small cell lung carcinoma. Cancer Cell 2010; 18: 63-73.

Patnaik A, Rosen LS, Tolaney SM, et al. Efficacy and safety of abemaciclib, an inhibitor of CDK4 and CDK6, for patients with breast cancer, non-small cell lung cancer, and other solid tumors. Cancer Discov 2016; 6: 740-753.

Hierro C, Rodon J, Tabernero J. Fibroblast growth factor (FGF) receptor/FGF inhibitors: novel targets and strategies for optimization of response of solid tumors. Semin Oncol 2015; 42: 801-819.

Brunner AM, Costa DB, Heist RS, et al. Treatment-related toxicities in a phase II trial of dasatinib in patients with squamous cell carcinoma of the lung. J Thorac Oncol 2013; 8: 1434-1437.

ansteenkiste JF, Canon J-L, Braud FD, et al. Safety and efficacy of buparlisib (BKM120) in patients with PI3K pathway-activated non-small cell lung cancer: results from the phase II BASALT-1 study. J Thorac Oncol 2015; 10: 1319-1327.

Soria J-C, Mauguen A, Reck M, et al. Systematic review and meta-analysis of randomised, phase II/III trials adding bevacizumab to platinum-based chemotherapy as first-line treatment in patients with advanced non-small-cell lung cancer. Ann Oncol 2013; 24: 20-30.

Cortot AB, Audigier-Valette C, Molinier O, et al. Weekly paclitaxel plus bevacizumab versus docetaxel as second or third-line treatment in advanced non-squamous non-small cell lung cancer (NSCLC): results from the phase III study IFCT-1103 ULTIMATE. J Clin Oncol 2016; 34: Suppl., abstr 9005.

Reck M, Kaiser R, Mellemgaard A, et al. Docetaxel plus nintedanib versus docetaxel plus placebo in patients with previously treated non-small-cell lung cancer (LUME-Lung 1): a phase 3, double-blind, randomised controlled trial. Lancet Oncol 2014; 15: 143-155.

Garon EB, Ciuleanu T-E, Arrieta O, et al. Ramucirumab plus docetaxel versus placebo plus docetaxel for second-line treatment of stage IV non-small-cell lung cancer after disease progression on platinum-based therapy (REVEL): a multicentre, double-blind, randomised phase 3 trial. Lancet 2014; 384: 665-673.

Sandler A, Gray R, Perry MC, et al. Paclitaxel-carboplatin alone or with bevacizumab for non-small-cell lung cancer. N Engl J Med 2006; 355: 2542-2550.

Thatcher N, Hirsch FR, Luft AV, et al. Necitumumab plus gemcitabine and cisplatin versus gemcitabine and cisplatin alone as first-line therapy in patients with stage IV squamous non-small-cell lung cancer (SQUIRE): an open-label, randomised, controlled phase 3 trial. Lancet Oncol 2015; 16: 763-774.

1 Paz-Ares L, Mezger J, Ciuleanu TE, et al. Necitumumab plus pemetrexed and cisplatin as first-line therapy in patients with stage IV non-squamous non-small-cell lung cancer (INSPIRE): an open-label, randomised, controlled phase 3 study. Lancet Oncol 2015; 16: 328-337.

Gajewski TF, Schreiber H, Fu Y-X. Innate and adaptive immune cells in the tumor microenvironment. Nat Immunol 2013; 14: 1014-1022.

Carbone DP, Gandara DR, Antonia SJ, et al. Non-small-cell lung cancer: role of the immune system and potential for immunotherapy. J Thorac Oncol 2015; 10: 974-984.

Tartour E, Zitvogel L. Lung cancer: potential targets for immunotherapy. Lancet Respir Med 2013; 1: $551-563$. Schalper KA, Brown J, Carvajal-Hausdorf D, et al. Objective measurement and clinical significance of TILs in non-small cell lung cancer. J Natl Cancer Inst 2015; 107.

Vansteenkiste JF, Cho BC, Vanakesa T, et al. Efficacy of the MAGE-A3 cancer immunotherapeutic as adjuvant therapy in patients with resected MAGE-A3-positive non-small-cell lung cancer (MAGRIT): a randomised, double-blind, placebo-controlled, phase 3 trial. Lancet Oncol 2016; 17: 822-835. 
Giaccone G, Bazhenova LA, Nemunaitis J, et al. A phase III study of belagenpumatucel-L, an allogeneic tumour cell vaccine, as maintenance therapy for non-small cell lung cancer. Eur J Cancer 2015; 51: 2321-2329.

Butts C, Socinski MA, Mitchell PL, et al. Tecemotide (L-BLP25) versus placebo after chemoradiotherapy for stage III non-small-cell lung cancer (START): a randomised, double-blind, phase 3 trial. Lancet Oncol 2014; 15: 59-68. Thomas A, Giaccone G. Why has active immunotherapy not worked in lung cancer? Ann Oncol 2015; 26: 2213-2220.

Melero I, Gaudernack G, Gerritsen W, et al. Therapeutic vaccines for cancer: an overview of clinical trials. Nat Rev Clin Oncol 2014; 11: 509-524.

Motz GT, Coukos G. Deciphering and reversing tumor immune suppression. Immunity 2013; 39: 61-73.

Pardoll DM. The blockade of immune checkpoints in cancer immunotherapy. Nat Rev Cancer 2012; 12: $252-264$.

Topalian SL, Drake CG, Pardoll DM. Immune checkpoint blockade: a common denominator approach to cancer therapy. Cancer Cell 2015; 27: 450-461.

Gettinger SN, Horn L, Gandhi L, et al. Overall survival and long-term safety of nivolumab (anti-programmed death 1 antibody, BMS-936558, ONO-4538) in patients with previously treated advanced non-small-cell lung cancer. J Clin Oncol 2015; 33: 2004-2012.

Brahmer J, Reckamp KL, Baas P, et al. Nivolumab versus docetaxel in advanced squamous-cell non-small-cell lung cancer. $N$ Engl J Med 2015; 373: 123-135.

, et al. Nivolumab versus docetaxel in advanced nonsquamous non-small-cell lung cancer. N Engl J Med 2015; 373: 1627-1639.

Herbst RS, Baas P, Kim D-W, et al. Pembrolizumab versus docetaxel for previously treated, PD-L1-positive, advanced non-small-cell lung cancer (KEYNOTE-010): a randomised controlled trial. Lancet 2016; 387: 1540-1550.

Fehrenbacher L, Spira A, Ballinger M, et al. Atezolizumab versus docetaxel for patients with previously treated non-small-cell lung cancer (POPLAR): a multicentre, open-label, phase 2 randomised controlled trial. Lancet 2016; 387: 1837-1846.

Barlesi F, Park K, Ciardiello F, et al. Primary analysis from OAK, a randomized phase III study comparing atezolizumab with docetaxel in 2L/3L NSCLC. Ann Oncol 2016; 27: Suppl. 6, LBA44_PR.

Reck M, Rodriguez-Abreu D, Robinson AG, et al. Pembrolizumab versus chemotherapy for PD-L1-positive non-small-cell lung cancer. N Engl J Med 2016; 375: 1823-1833.

Socinski M, Creelan B, Horn L, et al. CheckMate 026: a phase 3 trial of nivolumab vs investigator's choice (IC) of platinum-based doublet chemotherapy (PT-DC) as first-line therapy for stage iv/recurrent programmed death ligand 1 (PD-L1)-positive NSCLC. Ann Oncol 2016; 27: Suppl. 6, LBA7_PR.

Langer CJ, Gadgeel SM, Borghaei H, et al. Carboplatin and pemetrexed with or without pembrolizumab for advanced, non-squamous non-small-cell lung cancer: a randomised, phase 2 cohort of the open-label KEYNOTE-021 study. Lancet Oncol 2016; 17: 1497-1508.

Hirsch FR, McElhinny A, Stanforth D, et al. PD-L1 Immunohistochemistry Assays for Lung Cancer: Results from Phase 1 of the Blueprint PD-L1 IHC Assay Comparison Project. J Thorac Oncol 2017; 12: $208-222$.

Garon EB, Rizvi NA, Hui R, et al. Pembrolizumab for the treatment of non-small-cell lung cancer. $N$ Engl J Med 2015; 372: 2018-2028.

Hellmann MD, Gettinger SN, Goldman JW, et al. CheckMate 012: Safety and efficacy of first-line (1L) nivolumab (nivo; N) and ipilimumab (ipi; I) in advanced (adv) NSCLC. J Clin Oncol 2016; 34: Suppl., abstr 3001.

Ribas A. Adaptive immune resistance: how cancer protects from immune attack. Cancer Discov 2015; 5: 915-919.

Zou W, Wolchok JD, Chen L. PD-L1 (B7-H1) and PD-1 pathway blockade for cancer therapy: mechanisms, response biomarkers, and combinations. Sci Transl Med 2016; 8: 328 rv4.

Rizvi NA, Hellmann MD, Snyder A, et al. Mutational landscape determines sensitivity to PD-1 blockade in non-small cell lung cancer. Science 2015; 348: 124-128.

Tumeh PC, Harview CL, Yearley JH, et al. PD-1 blockade induces responses by inhibiting adaptive immune resistance. Nature 2014; 515: 568-571.

Ribas A, Robert C, Hodi S, et al. Association of response to programmed death receptor 1 (PD-1) blockade with pembrolizumab (MK-3475) with an interferon-inflammatory immune gene signature. J Clin Oncol 2015; 33: Suppl., abstr 3001.

Larkin J, Chiarion-Sileni V, Gonzalez R, et al. Combined nivolumab and ipilimumab or monotherapy in untreated melanoma. N Engl J Med 2015; 373: 23-34.

Patnaik A, Socinski MA, Gubens MA, et al. Phase 1 study of pembrolizumab (pembro; MK-3475) plus ipilimumab (IPI) as second-line therapy for advanced non-small cell lung cancer (NSCLC): KEYNOTE-021 cohort D. J Clin Oncol 2015; 33: Suppl., abstr 8011.

Antonia S, Goldberg SB, Balmanoukian A, et al. Safety and antitumour activity of durvalumab plus tremelimumab in non-small cell lung cancer: a multicentre, phase 1b study. Lancet Oncol 2016; 17: $299-308$.

Rizvi NA, Hellmann MD, Brahmer JR, et al. Nivolumab in combination with platinum-based doublet chemotherapy for first-line treatment of advanced non-small-cell lung cancer. J Clin Oncol 2016; 34: 2969-2979.

Camidge DR, Liu SV, Powderly J, et al. Atezolizumab (MPDL3280A) combined with platinum-based chemotherapy in non-small cell lung cancer (NSCLC): a phase Ib safety and efficacy update. J Thorac Oncol 2015; 10: Suppl. 2, S176-S177.

Gadgeel SM, Stevenson J, Langer CL, et al. Pembrolizumab (pembro) plus chemotherapy as front-line therapy for advanced NSCLC: KEYNOTE-021 cohorts A-C. J Clin Oncol 2016; 34: Suppl., abstr 9016.

Tsui DWY, Berger MF. Profiling non-small cell lung cancer: from tumor to blood. Clin Cancer Res 2016; 22: $790-792$. 